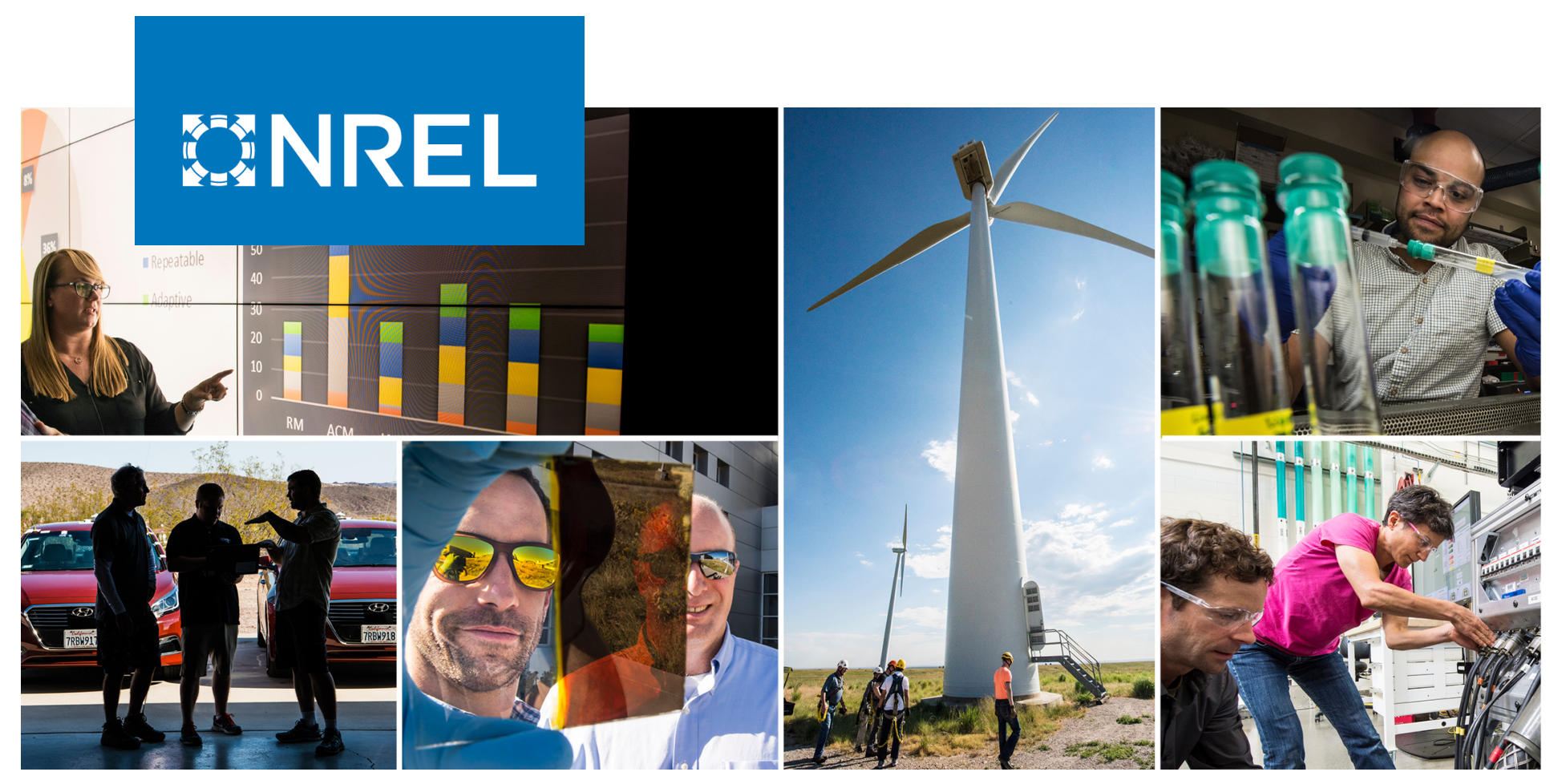

\title{
Biochemical Conversion of Lignocellulosic Biomass to Hydrocarbon Fuels and Products: 2020 State of Technology and Future Research
}

Ryan Davis, Andrew Bartling, and Ling Tao

National Renewable Energy Laboratory

NREL is a national laboratory of the U.S. Department of Energy

Office of Energy Efficiency \& Renewable Energy

Operated by the Alliance for Sustainable Energy, LLC

This report is available at no cost from the National Renewable Energy Laboratory (NREL) at www.nrel.gov/publications.
Technical Report

NREL/TP-5100-79930

May 2021 


\section{GNREL}

\section{Biochemical Conversion of Lignocellulosic Biomass to Hydrocarbon Fuels and Products: 2020 State of Technology and Future Research}

Ryan Davis, Andrew Bartling, and Ling Tao

National Renewable Energy Laboratory

\section{Suggested Citation}

Davis, Ryan, Andrew Bartling, and Ling Tao. 2021. Biochemical Conversion of Lignocellulosic Biomass to Hydrocarbon Fuels and Products: 2020 State of Technology and Future Research. Golden, CO:

National Renewable Energy Laboratory. NREL/TP-5100-79930.

https://www.nrel.gov/docs/fy21osti/79930.pdf.

NREL is a national laboratory of the U.S. Department of Energy Office of Energy Efficiency \& Renewable Energy Operated by the Alliance for Sustainable Energy, LLC

This report is available at no cost from the National Renewable Energy Laboratory (NREL) at www.nrel.gov/publications.

Contract No. DE-AC36-08GO28308
Technical Report

NREL/TP-5100-79930

May 2021

National Renewable Energy Laboratory 15013 Denver West Parkway Golden, CO 80401

303-275-3000 • www.nrel.gov 


\section{NOTICE}

This work was authored by the National Renewable Energy Laboratory, operated by Alliance for Sustainable Energy, LLC, for the U.S. Department of Energy (DOE) under Contract No. DE-AC36-08GO28308. Funding provided by U.S. Department of Energy Office of Energy Efficiency and Renewable Energy Bioenergy Technologies Office. The views expressed herein do not necessarily represent the views of the DOE or the U.S. Government.

This report is available at no cost from the National Renewable Energy Laboratory (NREL) at www.nrel.gov/publications.

U.S. Department of Energy (DOE) reports produced after 1991 and a growing number of pre-1991 documents are available free via www.OSTI.gov.

Cover Photos by Dennis Schroeder: (clockwise, left to right) NREL 51934, NREL 45897, NREL 42160, NREL 45891, NREL 48097, NREL 46526.

NREL prints on paper that contains recycled content. 


\section{Acknowledgments}

The authors wish to thank the following researchers for their contributions to this work: Rick Elander, Xiaowen Chen, Nancy Dowe, Davinia Salvachua, Gregg Beckham, Derek Vardon, Eric Karp, Patrick Saboe, Jake Kruger, Min Zhang, Mike Himmel, Jeff Linger, and Zia Abdullah from the National Renewable Energy Laboratory (NREL); David Thompson and Mohammad Roni from Idaho National Laboratory (INL); and Zhenglong Li from Oak Ridge National Laboratory (ORNL). This report provides a high-level overview of research data across key unit operations as utilized in updating NREL's State of Technology (SOT) benchmark models based on inputs furnished from those researchers; however, it is not intended to present an exhaustive summary of all research activities, methods, or data outputs, and we defer to those and others' research works for further context. 


\section{List of Acronyms}

$\mathrm{AD}$

ANL

APL

BCD

BDO

BETO

$\mathrm{CEH}$

CHP

COD

CUBI

DDA

DMR

EEO

$\mathrm{EH}$

FCIC

GGE

GHG

HDO

HED-ISPR

INL

IS

LCA

LHV

LTAD

MFSP

MVR

NREL

ORNL

$\mathrm{R} \& \mathrm{D}$

$\mathrm{RCF}$

SLS

SOT

SSF

TEA

TOPO

TS

WHSV

WWT anaerobic digestion

Argonne National Laboratory

alkaline pretreated liquors

base-catalyzed deconstruction (of lignin)

2,3-butanediol

Bioenergy Technologies Office

continuous enzymatic hydrolysis

combined heat and power

chemical oxygen demand

catalytic upgrading of biochemical intermediates (under ChemCatBio Consortium)

deacetylation and dilute acid (pretreatment)

deacetylation and mechanical refining (pretreatment)

Enzyme Engineering and Optimization (NREL research project)

enzymatic hydrolysis

Feedstock Conversion Interface Consortium

gallon gasoline equivalent

greenhouse gas

hydrodeoxygenation

Hybrid Extraction-Distillation with In Situ Product Recovery

Idaho National Laboratory

insoluble solids

life cycle analysis

lower heating value

Low-Temperature Advanced Deconstruction (NREL research project)

minimum fuel selling price

mechanical vapor recompression

National Renewable Energy Laboratory

Oak Ridge National Laboratory

research and development

reactive catalytic fractionation

solid-liquid separations

state of technology

simultaneous saccharification and fermentation

techno-economic analysis

tri-octyl-phosphene-oxide

total solids

weight hourly space velocity

wastewater treatment 


\section{Executive Summary}

The annual State of Technology (SOT) assessment is an essential activity for biochemical platform research. It allows the impact of research progress (both directly achieved in-house at the National Renewable Energy Laboratory [NREL] and indirectly extrapolated from available public data) to be quantified in terms of economic improvements in the overall cellulosic biofuel production process for a particular conversion pathway. As such, initial benchmarks can be established for currently demonstrated performance and progress can be tracked toward out-year goals to ultimately demonstrate cost-competitive cellulosic biofuel technology.

Building upon recent efforts to transition NREL's biochemical platform research and development (R\&D) work toward ultimate 2030 goals to demonstrate less than $\$ 2.50$ /gallon gasoline equivalent (GGE) fuel selling prices, experimental and techno-economic analysis (TEA) activities have primarily focused on "advanced" biochemical processing strategies to fuels and coproducts, guided by TEA modeling to highlight key barriers and priorities toward achieving this goal across a number of potential bioconversion pathways. The purpose of the present effort is to benchmark the latest experimental developments for these pathways as quantified by modeled minimum fuel selling prices (MFSPs), as a measure of current status relative to those final targets. For this SOT, TEA models were run for two separate biological conversion pathways to fuels, based on available data for integrated biomass deconstruction and hydrolysate processing; namely carboxylic acids (primarily butyric acid) and diols (2,3-butanediol [BDO]), reflecting NREL's recently published 2018 biochemical design report focused on those two pathways. The models were run across three scenarios for lignin utilization, namely combustion, conversion to coproducts based on "base case" performance with biomass hydrolysate, and conversion to coproducts based on "high" performance demonstrated with model lignin monomer components.

A key improvement reflected in the 2020 SOT is centered around a new two-stage deacetylation process, making use of a newly-added sodium carbonate extraction step prior to standard sodium hydroxide extraction, which was shown to enable substantial reductions in sodium hydroxide consumption during deacetylation pretreatment (historically a strong driver in both cost and environmental sustainability metrics for the overall biorefinery, with introduction of sodium carbonate as a much less costly and greenhouse gas-intensive alkali material). Under this approach, the most optimal conditions led to a $70 \%$ reduction in deacetylation sodium hydroxide loading, while also translating to very favorable downstream sugar yields from enzymatic hydrolysis at $88 \%$ glucan conversion, $>93 \%$ xylan conversion, and $91 \%$ arabinan conversion to monomeric sugars at a reduced $10 \mathrm{mg} / \mathrm{g}$ enzyme loading, nearly meeting or exceeding final targets for biomass deconstruction.

Downstream of enzymatic hydrolysis, although further experimental work was performed on sugar fermentation and upgrading steps, both pathways did not ultimately observe performance levels surpassing those from the 2019 SOT, and thus 2019 benchmarks were maintained for those operations. However, most associated conversion parameters were already quite favorable for both pathways, utilizing over $95 \%$ glucose and $89 \%$ xylose sugars at fermentation process yields approaching or exceeding future 2030 targets, coupled with encouraging catalytic upgrading data for both intermediate products to finished fuels/blend stocks at $100 \%$ conversions across nearly all steps under experimental investigation. Based on the combination of these 
process parameter values, the 2020 SOT MFSPs are estimated to be $\$ 6.80 / \mathrm{GGE}$ and $\$ 7.13 / \mathrm{GGE}$ (\$4.87/GGE and \$5.04/GGE conversion-only costs excluding feedstock contributions) in 2016 dollars for the BDO and acids pathways, respectively, attributed to the "burn lignin" basis scenario. These MFSPs are based on a total hydrocarbon fuel yield of 41.5 and $38.5 \mathrm{GGE} /$ ton dry biomass for the respective pathways. The 2018 feedstock cost as furnished by Idaho National Laboratory (INL) is $\$ 80.10$ /dry ton (2016\$), including a dockage fee to adjust to a 5\% ashequivalent basis for modeling purposes. These results translate to a reduction of $\$ 0.99 / \mathrm{GGE}$ and $\$ 1.07 /$ GGE (13\%) in overall MFSPs for the two respective pathways, driven primarily by the reduced costs and improved yields across deconstruction noted above.

The alternative SOT scenarios reflecting lignin conversion to coproducts indicated MFSP estimates of \$9.47/GGE and \$10.02/GGE for "base case" experimental lignin conversion performance on biomass hydrolysate (BDO and acids pathways, respectively); this would hypothetically reduce to $\$ 8.62 / \mathrm{GGE}$ and $\$ 9.04 / \mathrm{GGE}$ for "high" lignin conversion performance as observed for model lignin monomers. These results maintain that the lignin-to-coproduct train remains not yet economically profitable relative to burning the lignin, given higher costs for producing the adipic acid coproduct than the amount of resulting coproduct revenue generated (attributed in turn to low lignin deconstruction/conversion yields and fermentation productivities). There were no general improvements achieved for the key lignin coproduct TEA parameters in 2020 relative to initial demonstrated levels in the 2018 SOT, thus again highlighting this process area as a key priority moving forward for future focus in ultimately contributing to MFSP reductions toward 2030 goals.

Finally, this milestone reports on key process sustainability indicators for the biorefinery conversion models, including mass and carbon yields to fuels and coproducts, water consumption, and facility power balances/natural gas demands. In keeping with recent practices, formal life cycle analysis (LCA) sustainability metrics such as greenhouse gas emissions or fossil energy consumption are not calculated here, but will be deferred to partners at Argonne National Laboratory (ANL).

Table ES-1. Summary of MFSPs and Fuel Yields for 2020 SOT Cases Compared to 2017-2019 SOT

\begin{tabular}{|c|c|c|c|c|c|c|c|c|}
\hline & $\begin{array}{c}\text { BDO } \\
2017 \text { SOT } \\
\text { Burn } \\
\text { Lignin }\end{array}$ & $\begin{array}{c}\text { Acids } \\
2017 \text { SOT } \\
\text { Burn } \\
\text { Lignin }\end{array}$ & $\begin{array}{c}\text { BDO } \\
2018 \text { SOT } \\
\text { Burn } \\
\text { (Base) } \\
\text { [High] }^{\mathrm{a}}\end{array}$ & $\begin{array}{c}\text { Acids } \\
2018 \text { SOT } \\
\text { Burn } \\
\text { (Base) }^{\text {[High] }}\end{array}$ & $\begin{array}{c}\text { BDO } \\
2019 \text { SOT } \\
\text { Burn } \\
\text { (Base) }^{\text {[High] }}{ }^{a}\end{array}$ & 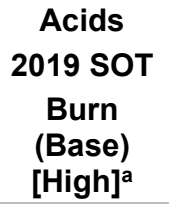 & $\begin{array}{c}\text { BDO } \\
2020 \text { SOT } \\
\text { Burn } \\
\text { (Base) } \\
\text { [High] }^{\text {a }}\end{array}$ & $\begin{array}{c}\text { Acids } \\
2020 \text { SOT } \\
\text { Burn } \\
\text { (Base) }^{\text {[High] }}\end{array}$ \\
\hline $\begin{array}{l}\text { Minimum Fuel Selling } \\
\text { Price (\$/GGE, 2016\$) }\end{array}$ & $\$ 10.08$ & $\$ 11.05$ & $\begin{array}{c}\$ 9.02 \\
(\$ 12.81) \\
{[\$ 11.54]}\end{array}$ & $\begin{array}{l}\$ 10.40 \\
(\$ 14.66) \\
{[\$ 13.16]}\end{array}$ & $\begin{array}{c}\$ 7.79 \\
(\$ 10.80) \\
{[\$ 9.72]}\end{array}$ & $\begin{array}{c}\$ 8.20 \\
(\$ 11.47) \\
{[\$ 10.29]}\end{array}$ & $\begin{array}{l}\$ 6.80 \\
(\$ 9.47) \\
{[\$ 8.62]}\end{array}$ & $\begin{array}{c}\$ 7.13 \\
(\$ 10.02) \\
{[\$ 9.04]}\end{array}$ \\
\hline $\begin{array}{l}\text { Feedstock Contribution } \\
(\$ / G G E, 2016 \$)\end{array}$ & $\$ 2.67$ & $\$ 3.19$ & $\$ 2.59$ & $\$ 2.99$ & $\$ 2.11$ & $\$ 2.30$ & $\$ 1.93$ & $\$ 2.09$ \\
\hline $\begin{array}{l}\text { Conversion } \\
\text { Contribution (\$/GGE, } \\
2016 \$ \text { ) }\end{array}$ & $\$ 7.41$ & $\$ 7.86$ & $\begin{array}{c}\$ 6.43 \\
(\$ 10.22) \\
{[\$ 8.95]}\end{array}$ & $\begin{array}{c}\$ 7.41 \\
(\$ 11.67) \\
{[\$ 10.17]}\end{array}$ & $\begin{array}{l}\$ 5.67 \\
(\$ 8.69) \\
{[\$ 7.61]}\end{array}$ & $\begin{array}{l}\$ 5.90 \\
(\$ 9.17) \\
{[\$ 7.98]}\end{array}$ & $\begin{array}{l}\$ 4.87 \\
(\$ 7.55) \\
{[\$ 6.70]}\end{array}$ & $\begin{array}{l}\$ 5.04 \\
(\$ 7.93) \\
{[\$ 6.96]}\end{array}$ \\
\hline $\begin{array}{l}\text { Hydrocarbon Fuel } \\
\text { Yield (GGE/dry ton) }\end{array}$ & 31.4 & 26.3 & 32.3 & 28 & 38.5 & 35.3 & 41.5 & 38.5 \\
\hline
\end{tabular}

a $(\#)=$ "base case" lignin conversion on biomass hydrolysate; [\#] = hypothetical "high" productivity with model lignin monomer compounds. 


\section{Table of Contents}

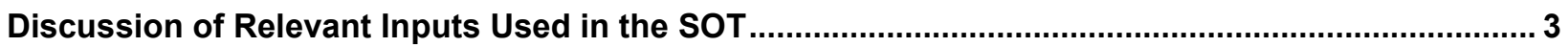

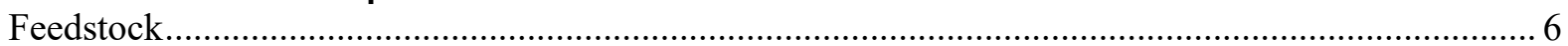

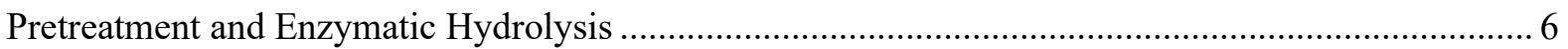

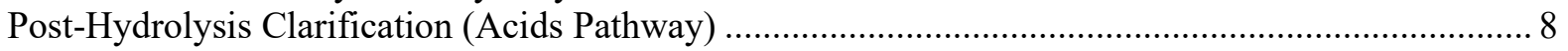

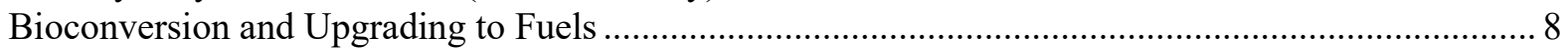

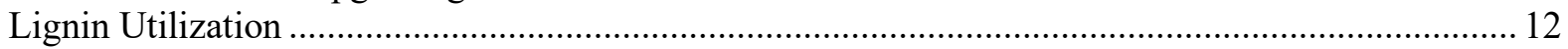

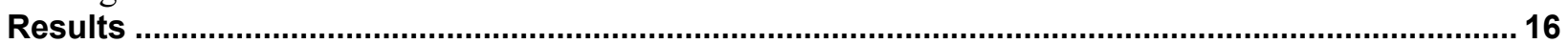

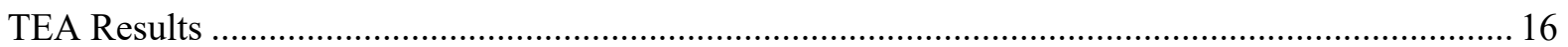

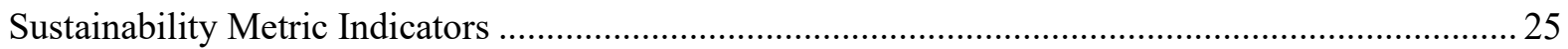

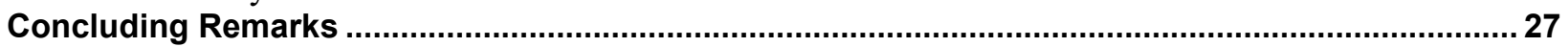

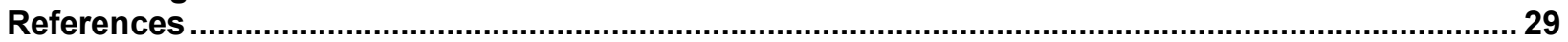

Appendix A. TEA Summary Sheets for 2020 SOT Benchmark Models (2016 dollars)..................... 31

Appendix B. Life Cycle Inventory (LCI) for 2020 SOT Benchmark Models ..................................... 37 


\section{Introduction}

The National Renewable Energy Laboratory (NREL) develops and maintains techno-economic models that describe the process and production economics of conceptual biochemical conversion pathways to biofuels and bioproducts. For a given set of conversion parameters, material and energy balance and flow rate information is generated using Aspen Plus process simulation software [1] assuming a feed rate to the biorefinery of 2,205 dry U.S. tons of biomass per day (2,000 metric tonne/day). These data are used to size and cost process equipment and compute raw material and other operating costs. Using a discounted cash flow rate of return analysis, the minimum fuel selling price (MFSP) required to obtain a net present value (NPV) of zero for a $10 \%$ internal rate of return (IRR) is determined. The result is a so-called technoeconomic model that reasonably estimates an " $n$th -plant" production cost for this pre-commercial process.

Recently, the Biochemical Platform Analysis project published the 2018 Biochemical Design Report Update (hereafter referred to as the 2018 design report), which documented the details and assumptions behind a techno-economic analysis (TEA) model focused on highlighting future technical targets required for achieving a modeled $n^{\text {th }}$-plant MFSP of $\$ 2.50 /$ gallon gasoline equivalent (GGE) or less by the year 2030 through biochemical processes [2]. Specifically, the report considered two separate pathways for biological and catalytic upgrading of lignocellulosic sugars to hydrocarbon fuels via carboxylic acid and diol intermediates, with associated upstream and downstream process integration considerations. These two pathways were selected among other bioconversion options being based on anaerobic fermentation, at considerable cost advantages relative to aerobic fermentation pathways (e.g., oleaginous yeast lipids) based on previously-demonstrated TEA findings summarized in a Go/No-Go decision milestone [3]. Both pathways included a deacetylation and mechanical refining (DMR) pretreatment step, followed by whole-slurry batch enzymatic hydrolysis in the diol case or continuous enzymatic hydrolysis with integrated solid/liquid separations in the acids case, followed by fermentation and recovery of the intermediate molecule and subsequent catalytic upgrading to hydrocarbon fuels. Both pathways also included supporting operations including wastewater treatment, waste solids/gas boiler and steam/power generation, and heating/cooling utilities. Finally, in order to ultimately achieve the MFSP targets below $\$ 2.50 / \mathrm{GGE}$, both pathways were shown to rely heavily on the inclusion of value-added coproducts (e.g., adipic acid) from lignin and other residual biomass, requiring approximately $50 \%$ conversion of biomass lignin to adipic acid, in addition to utilization of biomass extractives, unconverted carbohydrates, and other components, in order to reach this ultimate cost target.

The purpose of this report is to summarize recent R\&D progress based on 2020 experimental findings for the key process steps behind both of the design case pathways described above, and to quantify the resulting MFSPs in order to benchmark current state of technology (SOT) performance relative to the future design case targets. The intent of this report is not to provide an exhaustive documentation of all research activities pertaining to all steps under the aforementioned pathways, and we defer to the associated reports of the Platform R\&D projects for that information. Rather, this assessment focuses on quantifying the MFSP benchmarks attributed to the latest SOT performance for these pathways based on experimental data currently available for an integrated process. 
The annual SOT models follow an established practice in place since 2007 as a means to quantify the economic implications for observed experimental performance, by correlating experimental performance data for the various unit operations with modeled minimum fuel selling price on a dollar-per-GGE basis. This allows for both establishing cost benchmarks for a process pathway, as well as documenting progress moving beyond the initial benchmarks. With minimal changes to the unit operations in the Aspen Plus model, the projected conversions from the future target case are replaced by present conversions that have been (ideally) experimentally verified at the bench and/or pilot scale on process-relevant material. In cases where in-house experimental data do not yet exist, publicly available information such as that provided in published literature is occasionally utilized. By comparing the SOT year over year, research advances can be quantified in terms of their impact on overall biorefinery production economics to track progress toward final 2030 goals of $\$ 2.50 / \mathrm{GGE}$, as well as more near-term interim progress.

It should always be emphasized that our analyses and the resultant MFSP values carry some uncertainty related to the assumptions made about capital and raw material costs. Without a detailed understanding of the basis behind it, the absolute computed MFSP has limited relevance. MFSP values are therefore best used to compare technological variations or process improvements against one another. By demonstrating the cost impact of various process parameters individually or in concert, the model helps guide research by indicating where the largest opportunities for cost reduction exist. It is also acknowledged that "state of technology" is arguably a misnomer since no commercial cellulosic hydrocarbon biofuel plants exist today (based on biological conversion technology or bioproduct co-processing strategies). Furthermore, this report is not intended to represent the "state of the industry" including commercial organizations who have been developing aspects of the technology privately, and who may be further ahead than what is presented in public literature or NREL data regarding parameters related to biological conversion performance of engineered organisms. The majority of the unit operation conversion yields in the SOT stem primarily from laboratory-scale data for enzymatic hydrolysis, hydrolysate clarification, and sugar/lignin bioconversion operations, with pretreatment done at pilot scale. There is of course some risk in assuming that bench-scale performance data are applicable at larger scale, and a key aspect of R\&D efforts moving forward will be to scale operations up beyond bench-scale and otherwise pursue process integration operational strategies leading up to future demonstration targets. 


\section{Discussion of Relevant Inputs Used in the SOT}

The two design case target pathways as evaluated in the 2018 design report are depicted schematically in Figure 1. In summary, the overarching process designs are based on DMR pretreatment of herbaceous biomass, followed by enzymatic saccharification, hydrolysate conditioning (sugar concentration, applicable in the acids pathway), and bioconversion to hydrocarbon intermediates, which are then subsequently catalytically upgraded to hydrocarbon fuels/blend stocks. Solubilized lignin from the DMR stage is combined alongside the residual lignin solids recovered downstream, and routed through base catalyzed deconstruction (BCD) to further break lignin polymers down to soluble oligomers and subsequently fermented to muconic acid (along with solubilized extractives and carbohydrates), which is then hydrogenated to adipic acid as a value-added coproduct.

The "deacetylation" step in DMR is modeled in the design case as a continuous counter-current alkaline extraction unit with a screw press to dewater extracted biomass, sending the pressed liquor back through the operation to further concentrate the black liquor and (as a target) somewhat mitigate loss of hemicellulose carbohydrates. In the acids case, the hydrolysis step is based on the newer continuous enzymatic hydrolysis $(\mathrm{CEH})$ approach being investigated experimentally at NREL, utilizing a series of hydrolysis vessels each connected to microfilter/ultrafilter membranes to remove sugars and send solids/enzymes to the next stage. In the diols case (producing 2,3-butanediol [BDO]), the whole hydrolysate slurry is sent through fermentation, and solids are recovered afterwards in a lignin press, with the remaining aqueous BDO stream sent directly to catalytic upgrading. Both pathways include on-site wastewater treatment, albeit utilizing a simpler process without the need for anaerobic digestion (AD) in the target design cases given significantly lower chemical oxygen demand (COD) levels than prior designs. Finally, residual solids, wastewater sludge, and off-gas streams are combusted in a boiler connected to a steam turbine generator set to provide combined heat and power benefits to the facility.

Relative to the final design case targets to be achieved by 2030 for key operations as noted above, the processes evaluated in this SOT make a number of modifications based on current efforts (also reflected in Figure 1):

1. DMR step - deacetylation/alkaline extraction: While the future target asserts the use of a continuous counter-current alkaline extraction unit as described above and in the design report, experimentally this step currently maintains standard batch deacetylation as utilized in prior recent SOTs. However, a key update in the present SOT reflects a modification to a two-step batch deacetylation approach, adding a sodium carbonate preextraction stage prior to the typical sodium hydroxide extraction stage, as a means to reduce sodium hydroxide usage, which has been identified as a key driver in both economic and sustainability metrics.

2. Enzymatic hydrolysis - acids pathway: The new CEH concept is still in early stages of research, and not yet ready to be deployed to support this year's SOT in an integrated process. Accordingly, the process maintains standard batch hydrolysis (utilizing the same parameters as in the BDO pathway), followed by the flocculent-assisted vacuum filter press operation to perform in-line solid/liquid separations downstream of batch enzymatic 
hydrolysis (EH) (and then to sugar concentration via evaporation, as had also been utilized in the design case).

3. Fermentation - BDO pathway: While the design case assumes moving to fully anaerobic BDO fermentation by 2030 (with co-production of hydrogen to satisfy redox balances), this will require further strain engineering to accomplish moving forward. At present, the SOT model maintains the use of minimal oxygen delivery via an air overlay in the headspace of the fermentor vessel, consistent with the experimental approach and prior SOTs (no hydrogen co-production).

4. Fermentation - acids pathway: The design case assumed exclusive production of butyric acid to minimize recovery losses and maximize final carbon yields. The organism utilized in the present SOT has continued to improve on this aspect, moving from $90 \%$ butyric vs. acetic acid selectivity in the 2018 SOT to $98 \%$ in the 2019-2020 SOTs, thus nearly achieving exclusive production of butyric acid. However, the small amount of acetic acid still remaining is captured across pertraction and processed through catalytic upgrading.

5. Lignin utilization: Similar to 2018 (when lignin conversion to coproducts was first incorporated to the SOTs), the present SOT again reflects three lignin utilization scenarios, given that lignin deconstruction and upgrading is still in an earlier stage of research than most other operations and the performance for this process train again translates to a higher cost penalty on overall MFSP than simply burning lignin. Both fuel pathways consider the following scenarios for lignin utilization:

A. Convert lignin under base case conversion parameters observed with actual lignin hydrolysates

B. Convert lignin under higher conversion parameters observed with pure model lignin monomer compounds

C. Route all lignin to the boiler to provide more consistent results for comparison with prior SOTs

i. In case \#3 (burn lignin), the resulting COD concentration to the wastewater treatment (WWT) system increases as deacetylation black liquor is routed directly to WWT rather than the coproduct train; accordingly, the WWT system reverts to the full set of operations as had been utilized in prior designs, namely again including the anaerobic digestion step at increased WWT system costs. 

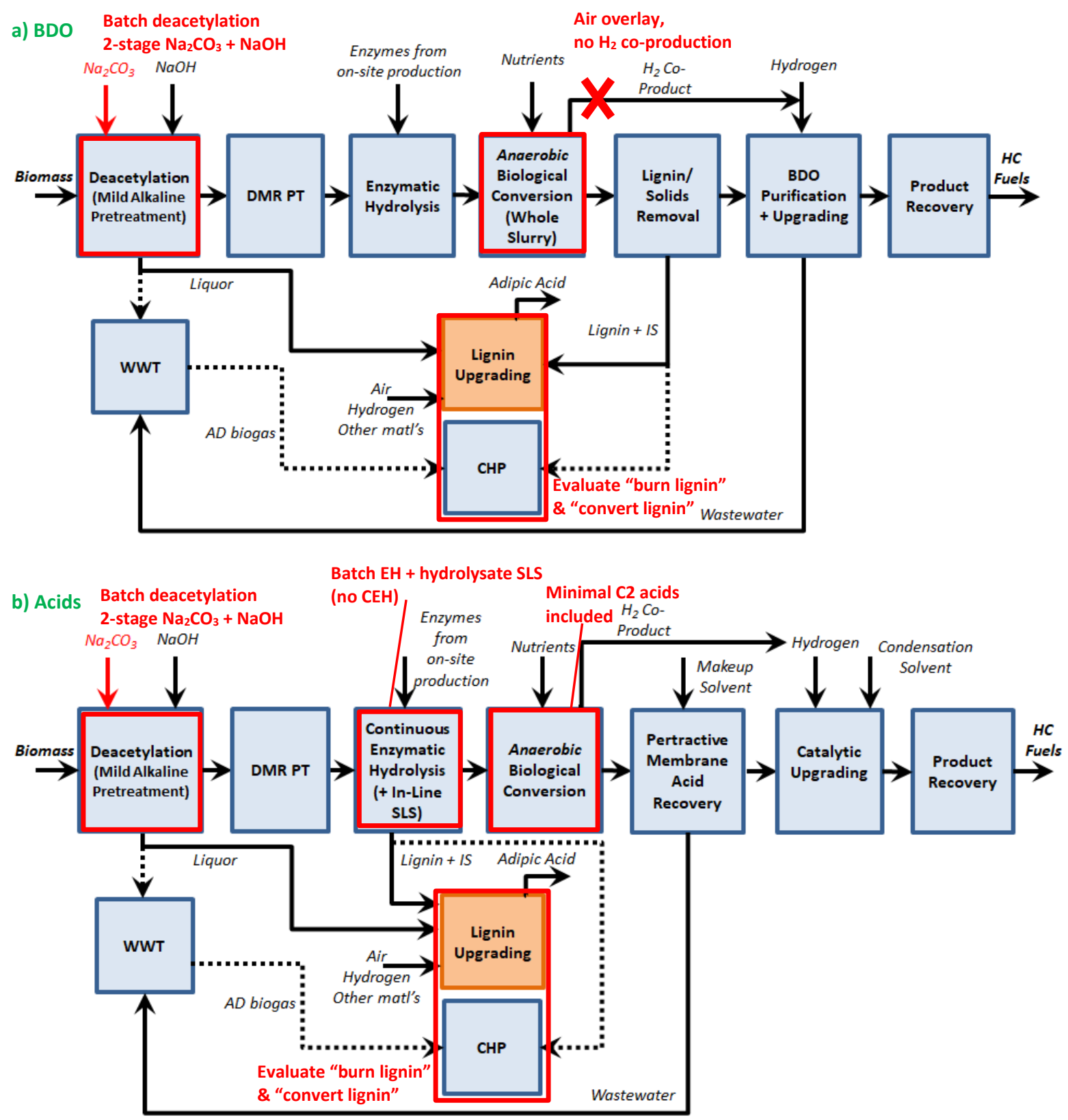

Figure 1. Block diagram schematics for 2030 "advanced process" configurations as projected in 2018 design report [2]. Modifications from the 2030 goals as reflected in the current 2020 SOT are denoted in red. 


\section{Feedstock}

Consistent with prior years, feedstock assumptions for the SOT between 2017 and 2020 are based on inputs provided annually by partners at Idaho National Laboratory (INL). Also similar to prior SOTs, as the primary focus of this work is to isolate the impacts of technology performance improvements strictly within the confines of the conversion process, this requires assuming a fixed biomass composition across all projected years to avoid artificial yield variances tied to varying feedstock compositions (i.e., ash content). INL's updated herbaceous feedstock cost guidelines allow for maintaining a fixed ash composition in the biorefinery conversion model, by way of valorizing ash variances using "dockage costs" on the feedstock side relative to the target 5\% ash content (personal communication with Erin Searcy, INL, September 2015). Table 1 presents the resulting feedstock costs for a " $5 \%$ ash-equivalent" feedstock, along with the underlying dockage fees associated with the variance from $5 \%$ for any given year (allowing us to keep ash and all other compositional details constant in our SOT models). These costs are largely consistent with those utilized in previous SOT assessments, but now updated to 2016-year dollars. All other feedstock components were set consistent with the compositional basis presented in our 2018 design report, including 59\% total carbohydrates, 16\% lignin, etc. $[2,4]$. In the 2020 SOT, INL achieved a roughly $2 \%$ reduction in delivered feedstock cost relative to the 2019 basis, at $\$ 80.10$ /dry ton inclusive of the above dockage adjustments (personal communication with David Thompson, INL, November 2020).

Table 1. Feedstock Costs Adjusted to 5\% Ash for Years 2017-2020 (2016-year dollars; courtesy of David Thompson and Mohammad Roni, INL)

\begin{tabular}{lcccc}
\hline & $\mathbf{2 0 1 7}$ & $\mathbf{2 0 1 8}$ & $\mathbf{2 0 1 9}$ & 2020 \\
\hline $\begin{array}{l}\text { Total feedstock cost to biorefinery at 5\% ash } \\
\text { equivalent (\$/dry ton) }\end{array}$ & $\$ 83.90$ & $\$ 83.67$ & $\$ 81.37$ & $\$ 80.10$ \\
Ash dockage vs. 5\% baseline (\$/dry ton) a & $\$ 1.26$ & $\$ 1.24$ & $\$ 1.58$ & $\$ 1.39$ \\
\hline
\end{tabular}

a Ash dockage fee is included in the overall "cost to biorefinery" and accounts for variances in ash content above $5 \%$ projected by INL (personal communication with INL, Sept. 2015-Nov. 2020)

\section{Pretreatment and Enzymatic Hydrolysis}

Given the recent shift in focus toward including lignin deconstruction and conversion to coproducts in the integrated processes (as a key prerequisite to ultimately achieving $\$ 2.50 / \mathrm{GGE}$ or even $\$ 3 /$ GGE goals in the future), this precludes the use of dilute acid pretreatment approaches and instead requires DMR in order to maintain convertible lignin throughout the process, while also enabling cleaner sugars with less salts and inhibitors. As noted above, while the DMR operation is ultimately projected to be performed with the use of a continuous countercurrent alkaline extraction unit in order to better concentrate the black liquor components, conserve water, and mitigate hemicellulose solubilization losses [2], batch deacetylation continues to serve as the benchmark operation for SOT purposes at present. A similar concept has been demonstrated experimentally through reverse-sequence batch recycling of black liquor [5], but this would incur a complex system of numerous batch reactors and holding tanks, which would not likely be economical for this process focused on commodity fuels. Accordingly, the present SOT reverts to the more simplistic batch deacetylation approach as utilized in the prior 2017-2019 SOTs. 
However, one key difference in the current SOT relative to prior efforts is the addition of a preextraction stage prior to the standard sodium hydroxide $(\mathrm{NaOH})$ deacetylation step. This was implemented as an outcome of recent additional focus placed on the substantial usage demands of $\mathrm{NaOH}$ and resultant challenges incurred on both economics and more strongly on biorefinery greenhouse gas (GHG) emissions highlighted through life cycle analysis (LCA) modeling. Namely, $\mathrm{NaOH}$ usage contributed approximately \$1/GGE to overall MFSP costs in the 2019 SOT ("burn lignin" BDO pathway scenario), roughly $\$ 0.40 /$ GGE of which was subsequently offset by sale of neutralized sodium sulfate salt as a coproduct from wastewater treatment [6]. Likewise, $\mathrm{NaOH}$ usage was one of the single largest contributors to overall biorefinery GHG emissions as reflected in Argonne National Laboratory's (ANL's) Supply Chain Sustainability Analysis for the 2019 SOT [7]. Accordingly, in 2020 NREL's Low-Temperature Advanced Deconstruction (LTAD) project focused research efforts on a two-stage deacetylation approach making use of sodium carbonate $\left(\mathrm{Na}_{2} \mathrm{CO}_{3}\right)$ as a "sacrificial" alkali material to neutralize acetate and other components of the incoming biomass feedstock, removing the liquor and then subjecting the resultant solids to standard $\mathrm{NaOH}$ extraction, followed by mechanical refining and Szego milling ("two-stage DMR"). Although $\mathrm{Na}_{2} \mathrm{CO}_{3}$ is a weak base and cannot likely fully take the place of $\mathrm{NaOH}$ in DMR pretreatment, its supplemental use to reduce $\mathrm{NaOH}$ consumption was hypothesized to lead to net benefits in cost and GHG emissions, given a threefold reduction in both parameters per unit mass compared to $\mathrm{NaOH}$ (see Table 2).

Table 2: Comparison of Key TEA and LCA Metrics for Sourcing of $\mathrm{NaOH}$ Versus $\mathrm{Na}_{2} \mathrm{CO}_{3}$

\begin{tabular}{|l|l|l|l|l|}
\hline & \multicolumn{2}{|l|}{$\begin{array}{l}\text { LCA metrics per ANL's Greenhouse Gases, } \\
\text { Regulated Emissions, and Energy Use in } \\
\end{array}$} & $\begin{array}{l}\text { TEA metrics } \\
\text { Transportation (GRET) model }\end{array}$ & $\begin{array}{l}\text { used in NREL } \\
\text { modeling }\end{array}$ \\
\cline { 2 - 5 } & $\begin{array}{l}\text { GHG } \\
(\mathbf{k g ~ C O} \mathbf{e} / \mathbf{k g})\end{array}$ & $\begin{array}{l}\text { Fossil Energy } \\
(\mathbf{M J} / \mathbf{k g})\end{array}$ & $\begin{array}{l}\text { Total Energy } \\
(\mathbf{M J} / \mathbf{k g})\end{array}$ & $\begin{array}{l}\text { Chemical Cost } \\
\mathbf{( \$ / k g )}\end{array}$ \\
\hline $\mathrm{NaOH}(100 \%)$ & 2.1 & 28.9 & 32.3 & $\$ 0.53$ \\
\hline $\mathrm{Na}_{2} \mathrm{CO}_{3}(100 \%)^{a}$ & 0.7 & 5.93 & 5.94 & $\$ 0.19$ \\
\hline
\end{tabular}

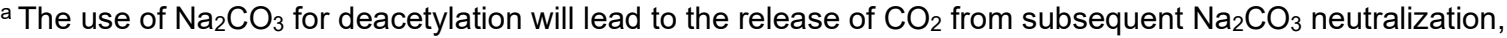
increasing the overall GHG emissions profile to roughly $1.0 \mathrm{~kg} / \mathrm{kg}$.

After evaluating a number of conditions for $\mathrm{Na}_{2} \mathrm{CO}_{3}$ and $\mathrm{NaOH}$ loading, as well as solids concentrations through enzymatic hydrolysis, the LTAD project identified a number of promising scenarios resulting in higher sugar yields at lower $\mathrm{NaOH}$ loadings relative to the basis utilized in the 2019 SOT of $80 \mathrm{~kg} \mathrm{NaOH} /$ dry tonne biomass [8]. Moreover, the results were demonstrated to be even more encouraging as they simultaneously allowed for reduced enzyme loadings relative to the 2019 SOT basis, and solids loadings potentially as high as $22.5 \%$ through enzymatic hydrolysis (albeit at slightly lower sugar yields compared to 20\% solids levels). Upon subsequent investigation of TEA and LCA trade-offs for all scenarios considered in the LTAD data set, the optimal case was identified at a $\mathrm{Na}_{2} \mathrm{CO}_{3}$ and $\mathrm{NaOH}$ loading of 80 and $24 \mathrm{~kg} / \mathrm{dry}$ tonne biomass, respectively, with each step performed sequentially at $90^{\circ} \mathrm{C}$ and 2-hour batch time. This translated to $88 \%$ and $93 \%$ conversions of glucan to glucose and xylan to xylose, respectively, demonstrated using a total enzyme loading of $10 \mathrm{mg} / \mathrm{g}$ cellulose $(8 \mathrm{mg}$ cellulase and $2 \mathrm{mg}$ hemicellulase enzymes) at 20\% total solids loading (the original data indicated even higher xylan conversion at $96 \%$, but with an additional $7 \%$ conversion of both glucan and xylan to oligomers; thus, xylan to xylose conversion was conservatively reduced to $93 \%$ to stay under 
$100 \%$ overall conversion). This represented a notable improvement over the base case at $87 \%$ and $84 \%$ glucan/xylan conversion at that same enzyme loading, as well as over the 2019 SOT basis of $84 \%$ and $82 \%$ conversions at $12 \mathrm{mg} / \mathrm{g}$ enzyme loading, while also reducing $\mathrm{NaOH}$ usage by $70 \%$ by supplementation with less cost- and GHG-intensive $\mathrm{Na}_{2} \mathrm{CO}_{3}$ alkali. Recent $\mathrm{BDO}$ fermentations using this new hydrolysate material showed no inhibition to the microorganism. Sugar utilization rates and product yield was equal to the pure sugar control.

The two-stage deacetylation operation produced a black liquor product containing roughly $13 \%$ of the original biomass xylan, $3 \%$ of the glucan, $48 \%$ of the arabinan, $11 \%$ of the ash, and $100 \%$ of the acetates, along with solubilizing $20 \%$ of the biomass lignin. In the "convert lignin" scenarios for adipic acid co-production, this liquor stream is routed to the lignin coproduct train to be (partially) utilized for muconic/adipic acid. In the "burn lignin" SOT scenario, the liquor is routed to wastewater treatment, which requires reverting back to the full WWT section, including the anaerobic digestion step as originally designed in prior TEA models $[4,9]$. The power for the subsequent mechanical refining step was set at $200 \mathrm{kWh} /$ dry ton biomass, consistent with vendor inputs provided previously [10].

\section{Post-Hydrolysis Clarification (Acids Pathway)}

For the acids pathway, following batch EH, the hydrolysate is sent through a solid/liquid separation unit (vacuum filter belt) to remove lignin and other residual insoluble solids as required for downstream bioreactor operation; this step is not required for the BDO pathway, as BDO fermentation data was maintained reflecting whole slurry rather than clarified sugars. All parameters for the vacuum belt filtration step are maintained consistently with those utilized in prior recent SOTs. As documented previously, recent experimental work with vacuum belt filtration has established that this is a challenging operation when placed downstream of the EH step given finer and less-filterable particles present in this location. Accordingly, sugar retention has been demonstrated at 95\% ( $5 \%$ loss to the solids product), which is not envisioned to be increased significantly moving forward, and the same $95 \%$ basis is maintained here.

Additionally, this occurs using a water wash to assist with sugar retention, set at a wash ratio of $17.5 \mathrm{~L} / \mathrm{kg}$ insoluble solids (IS), filter capacity of $12 \mathrm{~kg} \mathrm{IS} / \mathrm{m}^{2} \mathrm{~h}$, and assistance of a flocculant (branched polyamide with cationic charges) which is utilized at a loading of $20 \mathrm{~g} / \mathrm{kg}$ IS, consistent with prior benchmarks for this operation with DMR-pretreated hydrolysate (which is considerably more challenging to filter than deacetylation and dilute acid (DDA)-pretreated hydrolysate, and the operational parameters reflect this accordingly) [11]. Moving forward, once CEH is ready to be implemented in future SOTs, the vacuum filtration operation will be removed given that solid/liquid separation occurs as an integral aspect of CEH with the included microfiltration/ultrafiltration membrane steps (although further solids concentration will still make use of a lower-cost lignin press on the residual solids outlet stream).

\section{Bioconversion and Upgrading to Fuels}

While further experimental work was conducted over the course of 2020 for the fermentation and catalytic upgrading operations under both fuel pathways, COVID-19-related laboratory slowdowns and other factors incurred challenges such that performance for these operations did not exceed the levels previously demonstrated in the 2019 SOT; thus, 2019 SOT parameters were largely maintained for the fermentation and upgrading trains of both fuel pathways. Key details for these steps are summarized below (with further information provided in the 2019 SOT 
report [6]), along with a brief discussion of the activities performed and insights gained in the relevant tasks.

\section{Summary of SOT Input Parameters}

In the acids pathway, the clarified hydrolysate is routed to sugar concentration, and then to bioconversion. The clarified and concentrated hydrolysate undergoes anaerobic fermentation to convert sugars to mostly butyric acid, with a minimal amount of acetic acid co-produced at a roughly 50:1 mass ratio (less than $2 \mathrm{wt} \%$ acetic acid) using Clostridium tyrobutyricum. This represents a continued improvement over prior SOTs that had produced more acetic acid relative to butyric acid (acetic acid incurs significantly higher losses than butyric acid across both recovery as well as upgrading and phase separation). This was coupled with pertractive recovery of the acids as a key approach to maintaining economic viability compared to $\mathrm{pH}$-controlled fermentation with significant amounts of added caustic and subsequent salt disposal costs. In contrast to prior SOT experimental efforts, which generally performed acid fermentation in batch mode with separate operations to demonstrate fermentation and pertractive acid recovery in isolation, the 2019-2020 SOT efforts were done in a physically integrated system, with fermentation operated in fed-batch mode, coupled with continuous recovery of acids across a pertraction membrane. The conversion of sugars to products was set at $95 \%$ glucose (demonstrated), 95\% xylose (not fully demonstrated given logistical decisions for how the fedbatch system was operated with in situ acid removal, but expected to be realistic), and 20\% arabinose, with an additional $2.5 \%$ conversion to cell biomass for glucose/xylose and $9 \%$ for arabinose. Fermentation productivity was $0.62 \mathrm{~g} / \mathrm{L}-\mathrm{hr}$, roughly double that of the 2018 SOT basis at $0.3 \mathrm{~g} / \mathrm{L}-\mathrm{hr}$.

Recovery of acids was also maintained at $98.4 \%$ and $76.4 \%$ for butyric and acetic acids, respectively, based on a solvent system composed of $20 \%$ tri-octyl-phosphene-oxide (TOPO) plus $40 \%$ undecanone in mineral oil. In both the 2019 and 2020 SOT models, distillation is employed to boil the acids off from the heavier-boiling solvents as the commercially practical approach relative to use of $\mathrm{NaOH}$ back-extraction (given known significant penalties incurred with the required levels of $\mathrm{NaOH}$ to perform this operation). The recovered acids are next subjected to catalytic upgrading, based on data furnished by NREL researchers under the ChemCatBio catalytic upgrading of biochemical intermediates (CUBI) efforts. In brief, acid substrate first undergoes ketonization over a $\mathrm{ZrO}_{2}$ catalyst at $4 \mathrm{~h}^{-1}$ weight hourly space velocity (WHSV) and $435^{\circ} \mathrm{C}$, achieving $100 \%$ acid conversion with $93 \%$ selectivity to 4-heptanone; the remaining 7\% represents unknown ketones, but given experimental indications that this fraction follows a similar fate as 4-heptanone producing fuel grade hydrocarbons, the TEA model assumes complete conversion to the 4-heptanone component. The intermediate ketone stream is purified and routed to condensation to produce a mixture of $\mathrm{C} 9-\mathrm{C} 15$ oxygenated ketones/enones. All ketone condensation parameters remain similar to prior years, including use of a slurry reactor utilizing a $\mathrm{Nb}_{2} \mathrm{O}_{5}$ catalyst at a ratio of 1:4 wt catalyst:ketone, 10-hour residence time, and toluene solvent at a loading of 4:1 wt toluene:ketone, resulting in an overall process yield of 92 $\mathrm{wt} \%$ to enone products from feed ketones (after recycling unconverted ketones). Finally, the enone intermediates are upgraded to hydrocarbons via hydrodeoxygenation (HDO), again largely maintaining consistent details as prior SOTs including use of a $3 \% \mathrm{Pt}^{-} \mathrm{Al}_{2} \mathrm{O}_{3}$ catalyst at a WHSV of $4.7 \mathrm{~h}^{-1}$ and temperature of $334^{\circ} \mathrm{C}$, achieving $100 \%$ conversion to products (primarily $\mathrm{C} 14$ branched hydrocarbon from the C14-enone). 
For the BDO pathway, additional fermentation runs were conducted in 2020 on whole slurry hydrolysate, operated in fed-batch in an attempt to increase BDO titer over 2019 levels. Ultimately, while this did achieve a BDO titer of up to $80 \mathrm{~g} / \mathrm{L}$ compared to roughly $70 \mathrm{~g} / \mathrm{L}$ in 2019 , it also came at the expense of higher sugar diversion to glycerol at a ratio of approximately 1:6 versus BDO (it is likely that glycerol co-production could be reduced by increased agitation and/or aeration rates, but data is not yet available). Overall, the increased BDO titer was outweighed by a $13 \%$ reduction in BDO yield, which would lead to inferior TEA results, and thus the 2019 basis was maintained for this step as well. In summary, the 2019 BDO fermentation step achieved nearly $100 \%$ overall glucose utilization and $92 \%$ xylose utilization at 97\% metabolic yield to BDO (albeit no arabinose utilization) within 48 hours (roughly $1.4 \mathrm{~g} / \mathrm{L}-\mathrm{hr}$ productivity, a 30\% improvement over 2018). Moreover, with the fermentation process being based on whole slurry, the retention of enzymes from upstream EH promoted an additional 7.1\% yield of glucose and $2.0 \%$ of xylose from available oligomers relative to initial starting monomeric sugars. Acetoin byproduct yield was negligible, at $0.3 \% \mathrm{wt} \%$ of total BDO + acetoin production. These parameters are attributed to bench-scale experimental work done in a stirred 0.5-L batch reactor with an air overlay (air delivered to the headspace of the CSTR), rather than with dedicated air sparging into the broth, to demonstrate proof of concept that oxygen requirements for this pathway are minimal (limited strictly to satisfying redox balances).

For BDO catalytic upgrading, previous experimental data observed by Oak Ridge National Laboratory (ORNL) collaborators were also maintained given no further significant improvements over 2019 benchmarks, reflecting upgrading of 2,3-BDO over copper-based zeolite catalysts $(\mathrm{Cu} / \mathrm{PMFI})$. In the SOT model, the fermenter broth is first clarified in a lignin press (consistent with that used in prior ethanol work) and then sent to BDO polishing filtration, assumed to be two parallel skid units made up of microfiltration, nanofiltration, and ion exchange, including clean-in-place systems and backwash. The products from BDO catalytic upgrading were a mixture of butenes, propene, C5+ olefins, and methyl ethyl ketone (MEK). In the SOT models, $100 \%$ of the BDO is converted at $220^{\circ} \mathrm{C}$ based on inputs from ORNL for BDO upgrading performance. Hydrogen is added to the reactors at a hydrogen-to-BDO ratio of 7.2 (molar basis). The catalyst is costed at a WHSV of $1.0 \mathrm{~h}^{-1}$ with assumed annual catalyst replacement. The product mixture is then purified by simple distillation before subsequent oligomerization reactions of the olefin mixture to olefin oligomers. The oligomers (generally $\mathrm{C}_{4}-$ $\mathrm{C}_{20}$ olefins) are then hydrotreated to hydrocarbon fuels.

\section{Discussion of Latest R\&D Activities and Future Plans}

Under the Biological Upgrading of Sugars (BUS) project, research was focused on multiple facets as it relates to our process of using Clostridium tyrobutyricum as a microbial chassis for the production of butyric acid. From a process perspective, this project has worked in collaboration with the Separations Consortium to develop a process for Hybrid ExtractionDistillation with In Situ Product Recovery (HED-ISPR, as detailed below). We have further designed a pilot-scale reactor capable of producing tens of kilograms of butyric acid per run, encompassing fermentation, acid separation, and distillation. The major components for this mobile skid-based reactor have been purchased and we are optimistically hoping for construction and commissioning of this multi-stage reactor in FY 2021. From a strain-development perspective, we have been focusing on improving xylose utilization in the presence of glucose given diauxic growth with this strain. We have generated strains with a genetically decoupled xylose pathway and are currently evaluating these strains. We have further designed and 
constructed genetic cassettes to enable efficient utilization of arabinose. Further efforts have focused on laboratory-based evolution aimed at improving the low $\mathrm{pH}$ tolerance of $C$.

tyrobutyricum, which has the potential to dramatically increase overall productivity. Moving forward, a major FY 2021 goal is to build, commission, and optimize the pilot-scale reactor noted above. This will be essential to understanding the scaled viability of our process as well as for providing substantial material to downstream partners for conversion into fuels and chemicals. The second major thrust will be on strain and process improvement at the bench scale. We will leverage omics-guided strain engineering to understand and optimize cellular energetics, redox imbalances, and efficient carbon utilization during prolonged mixed-sugar fermentations. We will further work to improve individual aspects of the process, including increasing the low-pH tolerance of $C$. tyrobutyricum. Overall, our ultimate goal is to demonstrate this technology at pilot scale to enable butyric acid on par with cost targets for performance advantaged diesel blendstocks from acids.

Substantial work has been progressing under the Separations Consortium to further evaluate and optimize in situ pertractive recovery of carboxylic acids from fermentations. In 2020, this includes continued process integration to demonstrate acid separation from solvent utilizing distillation in place of $\mathrm{NaOH}$ back-extraction (though as noted above, the TEA model had already asserted the use of distillation given known penalties incurred for the required amount of $\mathrm{NaOH}$ that would be impractical at scale). The integrated work succeeded in producing $>100 \mathrm{~g}$ of $>98 \%$ butyric acid from hydrolysate at $\mathrm{pH} 5$ from a fully functional HED-ISPR system at the 10-L fermentation scale. Further work has been done to optimize solvent systems, membrane conditions, and heat integration. On the TEA side, over the course of 2020 the Biochemical Platform Analysis project consulted with an engineering subcontractor (Neoterics) to assist in improving/refining the level of granularity around the design and cost details of the pertractive recovery system, given higher uncertainties in the model for this novel technology. Although that subcontracting effort has just recently been completed, further work is still progressing under the Separations Consortium to compare TEA merits for pertractive membrane recovery versus electro-deionization (EDI) and capacitive deionization (CDI), utilizing updated TEA details for both operations. Upon conclusion of that work, if pertraction remains as the more optimal solution for acid recovery in this particular context, the updated design/cost details based on subcontractor guidance will be incorporated into future TEA model updates. Pilot-scale integrated runs for the HED-ISPR system are planned in FY 2022 at the 100-150-L scale to produce $\sim 10 \mathrm{~kg}$ of purified butyric acid. These data will update the TEA model with critical parameters such as solvent recycling efficiency and recycle stream closure numbers obtained at the pilot scale.

Under CUBI efforts, research activities on acids catalytic upgrading have advanced carboxylic acid ketonization time-on-stream studies to over $100 \mathrm{~h}$ of continuous operation using a packed bed flow reactor with commercially available catalyst materials. Partial conversion and catalyst regeneration studies have also been performed to show the initial stability and regenerability of this ketonization catalyst. Kinetic and reactor modeling work is also underway to inform how catalyst performance and process conditions will scale when transitioning to catalyst extrudate form factors. In addition, the flexibility of butyric acid as a platform molecule for advantaged diesel fuel production was demonstrated as a follow-on effort to work within the Co-Optima consortia. Catalyst material and process development was advanced within CUBI to demonstrate the continuous production of 4-butoxyheptane, an ether diesel bioblendstock that displays 
twofold higher cetane number and fourfold lower sooting tendency than fossil diesel fuel [12, 13]. Preliminary techno-economic and life cycle assessment supports the potential of this catalytic upgrading pathway for producing performance advantage oxygenate diesel blendstocks from acids.

The BSRD project in FY 2020 began developing a whole slurry fed-batch fermentation to produce BDO at higher titers than can be achieved with a batch fermentation. There are several ways to approach feeding additional slurry to the fermentor to increase titer. One can start the batch phase with fully saccharified biomass slurry and then continue the fed-batch with the saccharified biomass. Logistically, this would be one of the easier methods since the saccharified slurry would be easy to pump. Another approach using whole slurry in a fed-batch fermentation is to partially saccharify the biomass and finish the saccharification process in the fermentation during both the batch and fed-batch phase or just the fed-batch phase. This has the potential to lessen sugar feedback inhibition on the enzyme because the organism would be consuming the sugars as the hydrolysis happens. Still another way is to start with either fully saccharified or partially saccharified biomass and feed non-hydrolyzed solids, which is essentially a simultaneous saccharification and fermentation (SSF) scenario. This would be a way to increase solids content in the fermentation, thus increasing sugar concentration and titer without adding additional water. This method also reduces sugar feedback inhibition on both the enzyme and the microorganism. While we were successful in feeding fully saccharified and partially saccharified whole slurry, which resulted in a slight increase in titer over the FY 2019 batch basis $(80 \mathrm{~g} / \mathrm{L}$ vs. $70 \mathrm{~g} / \mathrm{L}$ ), we could not achieve higher titers near $125 \mathrm{~g} / \mathrm{L}$ seen using concentrated liquor. However, we had one (not replicated) successful SSF where we fed non-hydrolyzed solids and achieved $100 \mathrm{~g} / \mathrm{L}$ BDO with less than $5 \mathrm{~g} / \mathrm{L}$ glycerol produced and all the glucose and xylose consumed. We will focus our efforts in FY 2021 on developing this SSF approach, which shows the potential for high titers with less byproducts and full sugar utilization. We will also revisit our aeration process control strategy when whole slurry is used to minimize glycerol production to improve the BDO process yield and thus MFSP.

Additional work under CUBI has also progressed around the ORNL direct 2,3-BDO catalytic upgrading pathway. Key 2020 accomplishments have included further understanding the reaction network for BDO to olefins, as well as varying operating conditions to achieve a range of product selectivities. Further work has been done to understand the impact of water on catalyst performance, with a range of values for water content not seen to significantly impact catalyst performance or coking, though some sintering was observed. Moving forward, future research plans will investigate BDO liquid phase upgrading to oxygenate intermediates such as MEK or dioxolane (joint with other laboratory collaborators), as well as exploring potential catalysts and conditions for upgrading BDO to epoxide chemical products.

\section{Lignin Utilization}

Similar to the fuel train fermentation/upgrading operations, further experimental work has been conducted over the course of 2020 focused on lignin deconstruction/conversion operations, including new/alternative processing approaches, but due to COVID-19 slowdowns and other confounding factors, the "base case" approach to lignin processing as reflected in the current SOT model framework did not achieve performance levels exceeding prior benchmarks from 2018/2019. Again, key SOT input parameters as maintained for the present SOT are briefly 
summarized below based on prior SOT updates, followed by a discussion on recent lignin upgrading activities and accomplishments.

\section{Summary of SOT Input Parameters}

Residual solids exiting hydrolysis (acids) or fermentation (BDO) and the DMR black liquor stream are processed further to allow economic valorization of the remaining lignin carbon. First, the streams are conditioned as needed to release lignin monomers and clarify the slurries of suspended solids. For the SOT models, the black liquor is sent directly to fermentation without further conditioning or clarifying (based on the approach taken experimentally). The residual hydrolysis solids undergo base-catalyzed deconstruction at conditions of $120^{\circ} \mathrm{C}$ solubilizing $85 \%$ of the solids. Bench-scale results have indicated degradation of carbohydrates in both the black liquor stream and the BCD liquor, which is modeled in the SOT as conversion to short-chain acids (e.g., lactic acid).

Experimental work in 2020 focused primarily on working for the first time with lignin streams derived from a series of filtration steps being investigated under the Separations Consortium, intended to isolate fractions of solubilized lignin based on molecular weight for more optimal processing. However, the ratio of acetate to aromatics was seen to exceed organism tolerance, and the cells died prematurely. Moving forward, this may be overcome by adjusting feeding rates to fermentation, but further work is not possible under the confines of the present SOT until calendar year 2021. Accordingly, similar to the 2019 SOT, the 2020 SOT maintains all lignin deconstruction/upgrading parameters consistent with those documented previously in the 2018 SOT [14]. Under that previous work, for the "base" lignin utilization case reflecting integrated hydrolysate, actual black liquor and BCD product streams were fed to a lignin-converting strain of P. putida. Experimental yields of muconic acid at $0.15 \mathrm{~g} / \mathrm{g}$ total solubilized lignin and productivities of $0.06 \mathrm{~g} / \mathrm{L}-\mathrm{hr}$ were observed for both streams. Based on the mass balance in the SOT model, this translates to an overall utilization of solubilized lignin of $16 \%$. In other words, current bench-scale work is achieving high solubilization of lignin but producing lignin species (monomers, dimers, trimers, etc.) that are not consumed in high fractions by the current strain and at a slow rate, generally a reflection of the current BCD conditions, which primarily cleave ester-linked monomers. This incomplete consumption and slow kinetics are actively under investigation to determine the presence and impact of inhibitory species and improve the deconstruction process to target more convertible species. As noted earlier, carbohydrates and other oxygenated organic species (e.g., extractives) are degraded to shorter acids prior to entering the lignin fermentation. In the current model, these degradation products remain unconsumed, eventually reaching the wastewater treatment area where they are degraded. Muconic acid produced in the fermentation is recovered and upgraded to adipic acid as per the target parameters in the 2018 design case [2].

To understand the impacts of the strain engineering efforts surrounding the lignin fermentation, a second "high-performance" conceptual lignin case was again included based on data with model compounds. This case maintains similar assumptions and parameters for the BCD and black liquor composition but differs through the muconic acid fermentation. In 2018, bench-scale data using mock lignin compounds (p-coumaric acid) showed improved productivities of $0.53 \mathrm{~g} / \mathrm{L}-/ \mathrm{hr}$ under more controlled and optimal conditions, with a muconic acid titer of $27 \mathrm{~g} / \mathrm{L}$. In 2019 , a higher titer was achieved at $48 \mathrm{~g} / \mathrm{L}$, but at a lower productivity of $0.40 \mathrm{~g} / \mathrm{L}-\mathrm{hr}$. As noted above, given a strong cost driver around productivity at such levels (until roughly $1.0 \mathrm{~g} / \mathrm{L}-\mathrm{hr}$, at which 
point the cost sensitivity begins to reduce) [2], along with no other process changes otherwise (i.e., regarding yield to convertible species), the 2018 basis was maintained to minimize MFSP for this model lignin compound scenario. Accordingly, this higher productivity was used to benchmark the impact of a more optimized hypothetical fermentation. Importantly, the overall muconic acid yield for this case was held constant at $0.15 \mathrm{~g} / \mathrm{g}$, as the conditioning and clarification steps are unchanged and the expected utilization of soluble lignin species would be identical with only $16 \%$ of total available lignin utilized by the strain. As improved analytical details become available on the complex BCD and black liquor, the added precision surrounding which specific species are inhibitory, utilized, and underutilized is expected to point toward improved strategies for tuning upstream conditioning and lignin deconstruction.

\section{Discussion of Latest R\&D Activities and Future Plans}

Progress in the lignin valorization space has been substantial in FY 2020, despite COVID-19related challenges in laboratory access and the requisite delays in research. In the Lignin Utilization project, the cleavage of $\mathrm{C}-\mathrm{O}$ and $\mathrm{C}-\mathrm{C}$ bonds is being actively and vigorously pursued via several parallel oxidation chemistries to enable a higher theoretical monomer yield and provide a higher amount of bioavailable carbon for microbial conversion. This work has shown promise using off-the-shelf oxidation chemistry that is applied for monomer synthesis in the petrochemical industry at large scale. We anticipate that autoxidation chemistry will be able to make substantial contributions to the FY 2021 SOT modeling exercises. In addition, we have made progress in generating higher monomer yields via alkaline oxidation $(>30 \%$ on a total lignin basis, representing a nearly twofold increase over the base case) in a low-salt aqueous solution that is suitable for biological upgrading. The alkaline oxidation approach currently requires low lignin concentrations that result in unfavorable economic prospects, but we expect that reaction engineering may allow similarly high yields at process-relevant concentrations.

In the Separations Consortium's lignin-related efforts, we have made significant progress in the recovery of aromatic compounds and aliphatic acids (e.g., acetate, lactate) from alkaline pretreated liquors (APL) in work led by NREL. Using several novel membrane-based setups, this has resulted in both molecular filtration to isolate species from APL that are $<400-500 \mathrm{Da}$, and highly concentrated (e.g., [acetate] $>100 \mathrm{~g} / \mathrm{L}$ ) relative to the APL from deacetylation. The aliphatic components of this material can serve as a useful carbon source for microbes instead of using glucose, which will represent a process cost savings. A preliminary TEA model for this molecular weight filtration approach has been conducted, and will be incorporated into FY 2022 SOT-related efforts. These materials were provided near the end of FY 2020 to the biological funneling efforts (vide infra), but the single experiment that time allowed before the submission of this report was unsuccessful, likely due to acetate toxicity - an issue that can be readily mitigated through bioprocess development and will be updated FY 2021.

In the Biological Lignin Valorization project, we have engineered a Pseudomonas putida KT2440 strain to be able to more efficiently convert aromatic monomers derived from lignin into cis,cis-muconate, ß-ketoadipate, and 2-pyrone-4,6-dicarboxylic acid (PDC). Preliminary TEA from NREL has shown that to make an $\sim \$ 1 /$ GGE contribution to the fuel selling price of a carbohydrate-based biofuel, we need to achieve a product yield $>40 \%$ from lignin at a productivity above $0.5 \mathrm{~g} / \mathrm{L}-\mathrm{hr}$. FY 2020 activities included achieving a titer of $49.7 \mathrm{~g} / \mathrm{L}$ for muconate and a titer of $44.7 \mathrm{~g} / \mathrm{L}$ for $\beta$-ketoadipate, but these product concentrations are both 
toxic to the strain at this level, and at productivities that still need substantial improvement. Thus, FY 2021 will focus on overcoming the titer ceiling and further improving productivity.

Lastly, in the Lignin-First Biorefinery Development project, we have worked to demonstrate that the reductive catalytic fractionation (RCF) process can be a viable alternative to deacetylation and mechanical refining that has a potentially much more advantageous lignin valorization route. This work included developing the first rigorous and comprehensive TEA and LCA model for the RCF process, developing novel strategies to make RCF a continuous process, and directly pursuing other process improvements identified by the TEA efforts to make this process competitive with deacetylation and mechanical refining. 


\section{Results}

\section{TEA Results}

Based on the details summarized above for experimental performance across the integrated processes, the 2020 SOT benchmark for the BDO pathway ("burn lignin" scenario) is estimated at an overall MFSP of \$6.80/GGE total or \$4.87/GGE for conversion-related costs (2016 dollars) excluding feedstock allocations, with feedstock cost set at $\$ 80.10$ /dry ton, associated with a $5 \%$ ash-equivalent biomass composition as described previously. This corresponds to an overall fuel yield of $41.5 \mathrm{GGE} /$ ton biomass $(23.8 \%$ carbon yield to fuels from starting biomass). Key process/TEA results are shown in Table 3, with further cost details provided in Appendix A. This result represents roughly $\$ 0.99 / \mathrm{GGE}(13 \%)$ lower MFSP relative to last year's 2019 SOT case for the BDO pathway (\$7.79/GGE in 2016 dollars) when viewed on comparable footing (i.e., based also on burning lignin in the 2019 case). This cost reduction is driven primarily by substantial gains made in biomass deconstruction, between both cost savings for reduced $\mathrm{NaOH}$ usage (total DMR alkali cost reductions from $\$ 0.99 / \mathrm{GGE}$ to $\$ 0.61 / \mathrm{GGE}$ due to savings moving to the two-stage deacetylation approach supplementing $\mathrm{NaOH}$ with less-costly $\mathrm{Na}_{2} \mathrm{CO}_{3}$ ) and lower enzyme usage (MFSP cost reductions from $\$ 0.59 / \mathrm{GGE}$ to $\$ 0.45 / \mathrm{GGE}$, reflecting a lower 10 versus $12 \mathrm{mg} / \mathrm{g}$ enzyme loading), as well as higher hydrolysis sugar yields increasing from $84 \%$ to $88 \%$ glucan and $82 \%$ to $>93 \%$ xylan conversions to sugars, leading to $8 \%$ overall fuel yield gains over 2019 .

Similar to the findings in last year's 2019 SOT, the 2020 SOT yield and MFSP results remain challenged by relatively high losses of carbohydrates (primarily xylan and arabinan) into the DMR liquor phase, at least relative to what may be possible with more mild deacetylation as had been utilized previously in DDA pretreatment; however, the conditions employed here for DMR are currently seen to provide the best pretreatment/hydrolysis efficacy and overall MFSP optimization when DMR is required, as is the case in moving toward lignin coproduct upgrading (which is also ultimately targeted to make use of the solubilized carbohydrates in the future). For the BDO pathway SOT scenarios reflecting lignin utilization, the MFSP is estimated at \$9.47/GGE for the "base case" fermentation performance on actual hydrolysate, which would hypothetically reduce to $\mathbf{\$ 8 . 6 2}$ GGE for the "high" performance basis on model lignin monomers (primarily higher productivity, while keeping muconic/adipic acid yields fixed). These results are associated with roughly $85 \%$ solubilization of residual solid lignin recovered from downstream processing, $16 \%$ of which is convertible across lignin fermentation at a muconic acid process yield of $0.16 \mathrm{~g} / \mathrm{g}$ total soluble lignin. Given the low fraction of convertible species in the solubilized lignin material, the overall adipic acid process yields are roughly $15 \%$ of their final 2030 targets $(2.2 \%$ vs. $14.8 \%$ overall carbon yield to adipic acid from starting biomass, respectively), which combined with 50\%-94\% lower fermentation productivities (and accordingly higher fermentation/processing costs), translates to a net cost penalty when lignin coproducts are included, reflecting higher costs to produce the coproduct than the revenue it generates. To date, lignin conversion performance remains the same as initially demonstrated in the 2018 SOT, which is not yet at a break-even point compared to lignin combustion; accordingly, significant room for improvement remains moving forward as the key factor in ultimately enabling future MFSP targets by 2030. 
Utilizing the inputs from experimental work for the carboxylic acids pathway ("burn lignin" scenario), an overall MFSP of \$7.13/GGE total or \$5.04/GGE for conversion-related costs (2016 dollars) excluding feedstock allocations is estimated for the 2020 SOT. This corresponds to an overall fuel yield of $38.5 \mathrm{GGE} /$ ton biomass $(22.5 \%$ carbon yield to fuels from starting biomass). Key process/TEA results are again shown in Table 3, with further cost details provided in Appendix A. Compared to last year's 2019 SOT basis at $\$ 8.20 / \mathrm{GGE}$, this represents an improvement of $\$ 1.07 / \mathrm{GGE}(13 \%)$, driven similarly by reduced costs and increased sugar yields across the biomass deconstruction operations with two-stage DMR and batch hydrolysis (consistent with the BDO case), with overall pretreatment and hydrolysis contributions to MFSP reduced by $13 \%$ and overall fuel yields increased by $9 \%$.

For the alternative acids pathway SOT scenarios reflecting lignin utilization, the MFSP is estimated at \$10.02/GGE for the "base case" fermentation performance on actual hydrolysate, which would hypothetically reduce to \$9.04/GGE for the "high" performance basis on model lignin monomers, based on maintaining the same lignin deconstruction and conversion parameters as noted above for the BDO case. Compared with the 2019 SOT results for the "base case" and "high" performance lignin coproduct scenarios, this leads to reductions of $\$ 1.51 / \mathrm{GGE}$ and $\$ 1.31 / \mathrm{GGE}$, respectively, although due exclusively to fuel train improvements given no change in the lignin train performance as noted above. As discussed in the 2019 SOT report [6], a 95\% conversion of xylose to acids was maintained here, as asserted to be realistic in an optimized sugar feeding/acids pertraction operation. Under the experimentally measured value of $70 \%$ overall xylose utilization (68\% to acids) as observed at the end of the fermentation run, this would translate to an MFSP of \$7.84/GGE for the burn lignin scenario as an example sensitivity point (roughly $10 \%$ higher MFSP), at a fuel yield of $\mathbf{3 4 . 7}$ GGE/ton (10\% lower yield). 
Table 3(a). BDO Pathway: Technical Summary Table for 2020 SOT Benchmark, 2017-2019 Back-Cast SOT, and Future 2030 Targets [2]

\begin{tabular}{|c|c|c|c|c|c|c|c|c|c|}
\hline & Units & 2017 SOT & 2018 SOT & 2018 SOT & 2019 SOT & 2019 SOT & 2020 SOT & 2020 SOT & $\begin{array}{c}2030 \\
\text { Projection }\end{array}$ \\
\hline Lignin Handling & - & $\begin{array}{l}\text { Burn } \\
\text { Lignin }\end{array}$ & $\begin{array}{l}\text { Burn } \\
\text { Lignin }\end{array}$ & $\begin{array}{c}\text { Convert } \\
\text { Lignin: } \\
\text { Base (High) a }\end{array}$ & Burn Lignin & $\begin{array}{c}\text { Convert } \\
\text { Lignin: } \\
\text { Base (High) a }\end{array}$ & Burn Lignin & $\begin{array}{c}\text { Convert } \\
\text { Lignin: } \\
\text { Base (High) a }\end{array}$ & $\begin{array}{l}\text { Convert } \\
\text { Lignin }\end{array}$ \\
\hline Projected Minimum Fuel Selling Price & \$/GGE & $\$ 10.08$ & $\$ 9.02$ & $\begin{array}{l}\$ 12.81 \\
(\$ 11.54)\end{array}$ & $\$ 7.79$ & $\begin{array}{l}\$ 10.80 \\
(\$ 9.72)\end{array}$ & $\$ 6.80$ & $\begin{array}{c}\$ 9.47 \\
(\$ 8.62)\end{array}$ & $\$ 2.47$ \\
\hline Feedstock Contribution & $\$ / G G E$ & $\$ 2.67$ & $\$ 2.59$ & $\$ 2.59$ & $\$ 2.11$ & $\$ 2.11$ & $\$ 1.93$ & $\$ 1.93$ & $\$ 1.65$ \\
\hline Conversion Contribution & \$/GGE & $\$ 7.41$ & $\$ 6.43$ & $\$ 10.22(\$ 8.95)$ & $\$ 5.67$ & $\$ 8.69(\$ 7.61)$ & $\$ 4.87$ & $\$ 7.55(\$ 6.70)$ & $\$ 0.82$ \\
\hline Total Gasoline Equivalent Yield & GGE/dry U.S. ton & 31.4 & 32.3 & 32.3 & 38.5 & 38.5 & 41.5 & 41.6 & 43.2 \\
\hline Adipic Acid Coproduct Yield & $\mathrm{lb} / \mathrm{dry}$ ton biomass & 0 & 0 & 40 & 0 & 42 & 0 & 39 & 266 \\
\hline \multicolumn{10}{|l|}{ Feedstock } \\
\hline Feedstock Cost ${ }^{b}$ & \$/dry U.S. ton & $\$ 83.90$ & $\$ 83.67$ & $\$ 83.67$ & $\$ 81.37$ & $\$ 81.37$ & $\$ 80.10$ & $\$ 80.10$ & $\$ 71.26$ \\
\hline \multicolumn{10}{|l|}{ Pretreatment } \\
\hline Method & - & DMR & DMR & DMR & DMR & DMR & DMR & DMR & DMR \\
\hline Solids Loading & wt $\%$ & $20 \%$ & $20 \%$ & $20 \%$ & $20 \%$ & $20 \%$ & $20 \%$ & $20 \%$ & $30 \%$ \\
\hline Temperature & ${ }^{\circ} \mathrm{C}$ & 92 & 92 & 92 & 90 & 90 & 90 & 90 & 92 \\
\hline Reactor Mode & $\begin{array}{l}\text { Batch vs. Counter- } \\
\text { Current }\end{array}$ & Batch & Batch & Batch & Batch & Batch & Batch & Batch & $\begin{array}{l}\text { Counter- } \\
\text { Current }\end{array}$ \\
\hline Total Loading: $\mathrm{NaOH}\left[\mathrm{Na}_{2} \mathrm{CO}_{3}\right]$ & mg/g dry biomass & 70 & 70 & 70 & 80 & 80 & $24[80]$ & $24[80]$ & 70 \\
\hline Net solubilized lignin to liquor & $\%$ & $47 \%$ & $47 \%$ & $47 \%$ & $50 \%$ & $50 \%$ & $20 \%$ & $20 \%$ & $47 \%$ \\
\hline Net solubilized glucan to liquor & $\%$ & $2 \%$ & $2 \%$ & $2 \%$ & $2 \%$ & $2 \%$ & $3 \%$ & $3 \%$ & $2 \%$ \\
\hline Net solubilized xylan to liquor & $\%$ & $17 \%$ & $17 \%$ & $17 \%$ & $16 \%$ & $16 \%$ & $12 \%$ & $12 \%$ & $10 \%$ \\
\hline Net solubilized arabinan to liquor & $\%$ & $46 \%$ & $46 \%$ & $46 \%$ & $46 \%$ & $46 \%$ & $48 \%$ & $48 \%$ & $30 \%$ \\
\hline \multicolumn{10}{|l|}{ Enzymatic Hydrolysis } \\
\hline Hydrolysis Configuration & Batch vs. CEH & Batch & Batch & Batch & Batch & Batch & Batch & Batch & Batch \\
\hline Total Solids Loading to Hydrolysis & wt $\%$ & $20 \%$ & $20 \%$ & $20 \%$ & $20 \%$ & $20 \%$ & $20 \%$ & $20 \%$ & $25 \%$ \\
\hline Enzymatic Hydrolysis Batch Time & days & 5 & 5 & 5 & 5 & 5 & 7 & 7 & 5 \\
\hline Hydrolysis Glucan to Glucose & $\%$ & $78 \%$ & $78 \%$ & $78 \%$ & $84 \%$ & $84 \%$ & $88 \%$ & $88 \%$ & $90 \%$ \\
\hline Hydrolysis Xylan to Xylose & $\%$ & $85 \%$ & $85 \%$ & $85 \%$ & $82 \%$ & $82 \%$ & $93 \%$ & $93 \%$ & $90 \%$ \\
\hline $\begin{array}{l}\text { Sugar Loss (into solid stream after EH } \\
\text { separation) }\end{array}$ & $\%$ & $5 \%$ & $\begin{array}{l}\mathrm{N} / \mathrm{A} \\
\text { (whole } \\
\text { slurry) }\end{array}$ & $\begin{array}{l}\text { N/A (whole } \\
\text { slurry) }\end{array}$ & $\begin{array}{l}\text { N/A (whole } \\
\text { slurry) }\end{array}$ & $\begin{array}{l}\text { N/A (whole } \\
\text { slurry) }\end{array}$ & $\begin{array}{l}\text { N/A (whole } \\
\text { slurry) }\end{array}$ & $\begin{array}{l}\text { N/A (whole } \\
\text { slurry) }\end{array}$ & $\begin{array}{l}\text { N/A (whole } \\
\text { slurry) }\end{array}$ \\
\hline \multicolumn{10}{|l|}{ Cellulase Enzyme Production } \\
\hline Enzyme Loading & $\mathrm{mg} / \mathrm{g}$ cellulose & 12 & 12 & 12 & 12 & 12 & 10 & 10 & 10 \\
\hline \multicolumn{10}{|c|}{ Fermentation, Catalytic Conversion, and Upgrading to Fuels } \\
\hline Bioconversion Volumetric Productivity & g/L/hour & 1.7 & 1.1 & 1.1 & 1.43 & 1.43 & 1.43 & 1.43 & 2.6 \\
\hline $\begin{array}{l}\text { Glucose to Product [total glucose } \\
\text { utilization] }^{\mathrm{c}}\end{array}$ & $\%$ & $\begin{array}{c}86 \% \\
{[100 \%]}\end{array}$ & $\begin{array}{c}95 \% \\
{[100 \%]}\end{array}$ & $95 \%[100 \%]$ & $\begin{array}{c}96 \% \\
{[99.6 \%]}\end{array}$ & $96 \%[99.6 \%]$ & $96 \%[99.6 \%]$ & $96 \%[99.6 \%]$ & $95 \%[98 \%]$ \\
\hline Xylose to Product [total xylose utilization] ${ }^{\mathrm{c}}$ & $\%$ & $\begin{array}{l}89 \% \\
{[97 \%]}\end{array}$ & $\begin{array}{c}90 \% \\
{[92 \%]}\end{array}$ & $90 \%[92 \%]$ & $89 \%[92 \%]$ & $89 \%$ [92\%] & $89 \%$ [92\%] & $89 \%$ [92\%] & $90 \%$ [92\%] \\
\hline
\end{tabular}




\begin{tabular}{|c|c|c|c|c|c|c|c|c|c|}
\hline & Units & 2017 SOT & 2018 SOT & 2018 SOT & 2019 SOT & 2019 SOT & 2020 SOT & 2020 SOT & $\begin{array}{c}2030 \\
\text { Projection }\end{array}$ \\
\hline Lignin Handling & - & $\begin{array}{l}\text { Burn } \\
\text { Lignin }\end{array}$ & $\begin{array}{l}\text { Burn } \\
\text { Lignin }\end{array}$ & $\begin{array}{c}\text { Convert } \\
\text { Lignin: } \\
\text { Base (High) a }\end{array}$ & Burn Lignin & $\begin{array}{c}\text { Convert } \\
\text { Lignin: } \\
\text { Base (High) a }\end{array}$ & Burn Lignin & $\begin{array}{c}\text { Convert } \\
\text { Lignin: } \\
\text { Base (High) a }\end{array}$ & $\begin{array}{l}\text { Convert } \\
\text { Lignin }\end{array}$ \\
\hline $\begin{array}{l}\text { Arabinose to Product [total arabinose } \\
\text { utilization] }^{c}\end{array}$ & $\%$ & $0 \%[0 \%]$ & $0 \%[0 \%]$ & $0 \%[0 \%]$ & $0 \%[0 \%]$ & $0 \%[0 \%]$ & $0 \%[0 \%]$ & $0 \%[0 \%]$ & $85 \%[89 \%]$ \\
\hline $\begin{array}{l}\text { Bioconversion Metabolic Yield [Process } \\
\text { Yield] }\end{array}$ & g/g sugars & $\begin{array}{c}0.44 \\
{[0.42]}\end{array}$ & $\begin{array}{c}0.47 \\
{[0.44]}\end{array}$ & $0.47[0.44]$ & $0.47[0.45]$ & $0.47[0.45]$ & $0.47[0.45]$ & $0.47[0.45]$ & $0.47[0.45]$ \\
\hline $\begin{array}{l}\text { Fermentation intermediate product } \\
\text { recovery }\end{array}$ & $w t \%$ & $99.7 \%$ & $96.8 \%$ & $96.8 \%$ & $97.7 \%$ & $97.7 \%$ & $97.7 \%$ & $97.7 \%$ & $96.4 \%$ \\
\hline Aqueous BDO Upgrading: WHSV & $h^{-1}$ & 1 & 1 & 1 & 1 & 1 & 1 & 1 & 2 \\
\hline $\begin{array}{l}\text { Aqueous BDO Upgrading: Per-pass } \\
\text { conversion }\end{array}$ & $\begin{array}{l}\text { wt } \% \text { to desired } \\
\text { products }\end{array}$ & $89 \%$ & $90 \%$ & $90 \%$ & $100 \%$ & $100 \%$ & $100 \%$ & $100 \%$ & $100 \%$ \\
\hline Oligomerization: WHSV & $\mathrm{h}^{-1}$ & 1 & 1 & 1 & 1 & 1 & 1 & 1 & 1 \\
\hline Oligomerization: Per-pass conversion & $\begin{array}{l}\text { wt } \% \text { to desired } \\
\text { products }\end{array}$ & $100 \%$ & $100 \%$ & $100 \%$ & $100 \%$ & $100 \%$ & $100 \%$ & $100 \%$ & $100 \%$ \\
\hline Hydrotreating: WHSV & $\mathrm{h}^{-1}$ & 5 & 5 & 5 & 5 & 5 & 5 & 5 & 5 \\
\hline Hydrotreating: Per-pass conversion & $\begin{array}{l}\text { wt } \% \text { to desired } \\
\text { products }\end{array}$ & $100 \%$ & $100 \%$ & $100 \%$ & $100 \%$ & $100 \%$ & $100 \%$ & $100 \%$ & $100 \%$ \\
\hline \multicolumn{10}{|l|}{ Lignin Processing to Coproduct } \\
\hline Solid Deconstruction to Soluble Lignin & $\begin{array}{l}\text { wt\% BCD lignin } \\
\text { feed }\end{array}$ & - & - & $85 \%$ e & - & $85 \%{ }^{\mathrm{e}}$ & - & $85 \%{ }^{\text {e }}$ & $53 \%$ \\
\hline Convertible Components in Soluble Lignin & $\begin{array}{l}\text { wt } \% \text { of total soluble } \\
\text { lignin (APL +BCD) }\end{array}$ & - & - & $16 \%$ & - & $16 \%$ & - & $16 \%$ & $98 \%$ \\
\hline Muconic Acid Process Yield from Lignin & $\mathrm{g} / \mathrm{g}$ soluble lignin & - & - & 0.15 & - & 0.16 & - & 0.16 & 1.59 \\
\hline Muconic Acid Metabolic Yield from Lignin & $\begin{array}{l}g / g \text { lignin } \\
\text { consumed }\end{array}$ & - & - & 0.93 & - & 0.93 & - & 0.93 & 0.93 \\
\hline $\begin{array}{l}\text { Overall Carbon Upgrading Efficiency to } \\
\text { Coproduct }^{d}\end{array}$ & $\mathrm{~mol} \%$ & - & - & $3.8 \%$ & - & $3.8 \%$ & - & $4.0 \%$ & $27.8 \%$ \\
\hline Muconic Acid Productivity & $\mathrm{g} / \mathrm{L} / \mathrm{hr}$ & - & - & $0.06(0.53)$ & - & $0.06(0.53)$ & - & $0.06(0.53)$ & 1 \\
\hline Adipic Acid Production & MMlb/yr & - & - & 29 & - & 30 & - & 29 & 193 \\
\hline
\end{tabular}

a 2018-2020 lignin conversion "base" case from actual black liquor/BCD hydrolysate; "high" case (in parentheses) = highest productivity observed to date based on model lignin monomers

${ }^{b}$ Feedstock costs shown here based on a $5 \%$ "ash equivalent" and $20 \%$ "moisture equivalent" basis for all years considered, consistent with values provided by Idaho National Laboratory for total feedstock costs and associated ash and moisture "dockage" costs for each year.

${ }^{\mathrm{c}}$ First number represents sugar conversion to desired product (BDO/acids); values in brackets indicate total sugar utilization (including biomass organism propagation).

${ }^{\mathrm{d}}$ Includes fermentation of all convertible components, product recovery (crystallization) efficiencies, and hydrogenation yields to adipic acid (overall convertible $\mathrm{C}$ to adipic acid)

e SOT assumes only post-EH lignin solids are routed through BCD; target cases route both lignin solids and DMR liquor through BCD. "Solubilized" lignin remains low in convertible components for SOT cases relative to future targets, translating to lower overall carbon efficiency to adipic acid coproduct. 
Table 3(b). Acids Pathway: Technical Summary Table for 2020 SOT Benchmark, 2017-2019 Back-Cast SOT, and Future 2030 Targets [2]

\begin{tabular}{|c|c|c|c|c|c|c|c|c|c|}
\hline & Units & 2017 SOT & 2018 SOT & 2018 SOT & 2019 SOT & 2019 SOT & 2020 SOT & 2020 SOT & $\begin{array}{c}2030 \\
\text { Projection }\end{array}$ \\
\hline Lignin Handling & - & $\begin{array}{l}\text { Burn } \\
\text { Lignin }\end{array}$ & $\begin{array}{c}\text { Burn } \\
\text { Lignin }\end{array}$ & $\begin{array}{c}\text { Convert } \\
\text { Lignin: } \\
\text { Base (High) a }\end{array}$ & Burn Lignin & $\begin{array}{c}\text { Convert } \\
\text { Lignin: } \\
\text { Base (High) a }\end{array}$ & Burn Lignin & $\begin{array}{c}\text { Convert } \\
\text { Lignin: } \\
\text { Base (High) a }\end{array}$ & $\begin{array}{l}\text { Convert } \\
\text { Lignin }\end{array}$ \\
\hline Projected Minimum Fuel Selling Price & \$/GGE & $\$ 11.05$ & $\$ 10.40$ & $\begin{array}{l}\$ 14.66 \\
(\$ 13.16)\end{array}$ & $\$ 8.20$ & $\begin{array}{l}\$ 11.47 \\
(\$ 10.29)\end{array}$ & $\$ 7.13$ & $\begin{array}{l}\$ 10.02 \\
(\$ 9.04)\end{array}$ & $\$ 2.49$ \\
\hline Feedstock Contribution & $\$ / G G E$ & $\$ 3.19$ & $\$ 2.99$ & $\$ 2.99$ & $\$ 2.30$ & $\$ 2.30$ & $\$ 2.08$ & $\$ 2.09$ & $\$ 1.59$ \\
\hline Conversion Contribution & $\$ / G G E$ & $\$ 7.86$ & $\$ 7.41$ & $\begin{array}{c}\$ 11.67 \\
(\$ 10.17)\end{array}$ & $\$ 5.90$ & $\begin{array}{l}\$ 9.17 \\
(\$ 7.98)\end{array}$ & $\$ 5.04$ & $\begin{array}{l}\$ 7.93 \\
(\$ 6.96)\end{array}$ & $\$ 0.90$ \\
\hline Total Gasoline Equivalent Yield & GGE/dry U.S. ton & 26.3 & 28 & 28 & 35.3 & 35.3 & 38.5 & 38.4 & 44.8 \\
\hline Adipic Acid Coproduct Yield & $\mathrm{lb} /$ dry ton biomass & 0 & 0 & 41 & 0 & 42 & 0 & 40 & 259 \\
\hline \multicolumn{10}{|l|}{ Feedstock } \\
\hline Feedstock Cost ${ }^{b}$ & \$/dry U.S. ton & $\$ 83.90$ & $\$ 83.67$ & $\$ 83.67$ & $\$ 81.37$ & $\$ 81.37$ & $\$ 80.10$ & $\$ 80.10$ & $\$ 71.26$ \\
\hline \multicolumn{10}{|l|}{ Pretreatment } \\
\hline Method & - & DMR & DMR & DMR & DMR & DMR & DMR & DMR & DMR \\
\hline Solids Loading & wt $\%$ & $20 \%$ & $20 \%$ & $20 \%$ & $20 \%$ & $20 \%$ & $20 \%$ & $20 \%$ & $30 \%$ \\
\hline Temperature & ${ }^{\circ} \mathrm{C}$ & 92 & 92 & 92 & 90 & 90 & 90 & 90 & 92 \\
\hline Reactor Mode & $\begin{array}{l}\text { Batch vs. Counter- } \\
\text { Current }\end{array}$ & Batch & Batch & Batch & Batch & Batch & Batch & Batch & $\begin{array}{l}\text { Counter- } \\
\text { Current }\end{array}$ \\
\hline Total Loading: $\mathrm{NaOH}\left[\mathrm{Na}_{2} \mathrm{CO}_{3}\right]$ & mg/g dry biomass & 70 & 70 & 70 & 80 & 80 & $24[80]$ & $24[80]$ & 70 \\
\hline Net solubilized lignin to liquor & $\%$ & $47 \%$ & $47 \%$ & $47 \%$ & $50 \%$ & $50 \%$ & $20 \%$ & $20 \%$ & $47 \%$ \\
\hline Net solubilized glucan to liquor & $\%$ & $2 \%$ & $2 \%$ & $2 \%$ & $2 \%$ & $2 \%$ & $3 \%$ & $3 \%$ & $2 \%$ \\
\hline Net solubilized xylan to liquor & $\%$ & $17 \%$ & $17 \%$ & $17 \%$ & $16 \%$ & $16 \%$ & $12 \%$ & $12 \%$ & $10 \%$ \\
\hline Net solubilized arabinan to liquor & $\%$ & $46 \%$ & $46 \%$ & $46 \%$ & $46 \%$ & $46 \%$ & $48 \%$ & $48 \%$ & $30 \%$ \\
\hline \multicolumn{10}{|l|}{ Enzymatic Hydrolysis } \\
\hline Hydrolysis Configuration & Batch vs. CEH & Batch & Batch & Batch & Batch & Batch & Batch & Batch & $\mathrm{CEH}$ \\
\hline Total Solids Loading to Hydrolysis & $w t \%$ & $20 \%$ & $20 \%$ & $20 \%$ & $20 \%$ & $20 \%$ & $20 \%$ & $20 \%$ & $7.60 \%$ \\
\hline Enzymatic Hydrolysis Batch Time & days & 5 & 5 & 5 & 5 & 5 & 7 & 7 & Continuous \\
\hline Hydrolysis Glucan to Glucose & $\%$ & $78 \%$ & $78 \%$ & $78 \%$ & $84 \%$ & $84 \%$ & $88 \%$ & $88 \%$ & $96 \%$ \\
\hline Hydrolysis Xylan to Xylose & $\%$ & $85 \%$ & $85 \%$ & $85 \%$ & $82 \%$ & $82 \%$ & $93 \%$ & $93 \%$ & $99 \%$ \\
\hline $\begin{array}{l}\text { Sugar Loss (into solid stream after EH } \\
\text { separation) }\end{array}$ & $\%$ & $5 \%$ & $5 \%$ & $5 \%$ & $5 \%$ & $5 \%$ & $5 \%$ & $5 \%$ & $1 \%$ \\
\hline \multicolumn{10}{|l|}{ Cellulase Enzyme Production } \\
\hline Enzyme Loading & $\mathrm{mg} / \mathrm{g}$ cellulose & 12 & 12 & 12 & 12 & 12 & 10 & 10 & 10 \\
\hline \multicolumn{10}{|c|}{ Fermentation, Catalytic Conversion, and Upgrading to Fuels } \\
\hline Bioconversion Volumetric Productivity & g/L/hour & 1.1 & 0.3 & 0.3 & 0.62 & 0.62 & 0.62 & 0.62 & 2 \\
\hline $\begin{array}{l}\text { Glucose to Product [total glucose } \\
\text { utilization] }^{c}\end{array}$ & $\%$ & $\begin{array}{c}86 \% \\
{[100 \%]}\end{array}$ & $90 \%[95 \%]$ & $90 \%$ [95\%] & $95 \%[97.5 \%]$ & $95 \%[97.5 \%]$ & $95 \%[97.5 \%]$ & $95 \%[97.5 \%]$ & $95 \%[100 \%]$ \\
\hline Xylose to Product [total xylose utilization] ${ }^{\mathrm{c}}$ & $\%$ & $\begin{array}{c}82 \% \\
{[100 \%]}\end{array}$ & $77 \%[90 \%]$ & $77 \%[90 \%]$ & $95 \%[97.5 \%]$ & $95 \%[97.5 \%]$ & $95 \%[97.5 \%]$ & $95 \%[97.5 \%]$ & $85 \%[100 \%]$ \\
\hline
\end{tabular}




\begin{tabular}{|c|c|c|c|c|c|c|c|c|c|}
\hline & Units & 2017 SOT & 2018 SOT & 2018 SOT & 2019 SOT & 2019 SOT & 2020 SOT & 2020 SOT & $\begin{array}{c}2030 \\
\text { Projection }\end{array}$ \\
\hline Lignin Handling & - & $\begin{array}{l}\text { Burn } \\
\text { Lignin }\end{array}$ & $\begin{array}{l}\text { Burn } \\
\text { Lignin }\end{array}$ & $\begin{array}{c}\text { Convert } \\
\text { Lignin: } \\
\text { Base (High) a }\end{array}$ & Burn Lignin & $\begin{array}{c}\text { Convert } \\
\text { Lignin: } \\
\text { Base (High) a }\end{array}$ & Burn Lignin & $\begin{array}{c}\text { Convert } \\
\text { Lignin: } \\
\text { Base (High) }{ }^{a}\end{array}$ & $\begin{array}{l}\text { Convert } \\
\text { Lignin }\end{array}$ \\
\hline $\begin{array}{l}\text { Arabinose to Product [total arabinose } \\
\text { utilization] }^{c}\end{array}$ & $\%$ & $\begin{array}{c}82 \% \\
{[100 \%]}\end{array}$ & $32 \%[38 \%]$ & $32 \%[38 \%]$ & $20 \%[29.0 \%]$ & $20 \%[29.0 \%]$ & $20 \%[29.0 \%]$ & $20 \%[29.0 \%]$ & $85 \%[87 \%]$ \\
\hline $\begin{array}{l}\text { Bioconversion Metabolic Yield [Process } \\
\text { Yield] }\end{array}$ & g/g sugars & $0.44[0.44]$ & $0.45[0.41]$ & $0.45[0.41]$ & $0.45[0.44]$ & $0.45[0.44]$ & $0.45[0.44]$ & $0.45[0.44]$ & $0.45[0.43]$ \\
\hline $\begin{array}{l}\text { Fermentation intermediate product } \\
\text { recovery }\end{array}$ & $w t \%$ & $\begin{array}{l}60 \%(\mathrm{C} 2) \\
95 \%(\mathrm{C} 4)\end{array}$ & $\begin{array}{l}60 \%(C 2) \\
95 \%(C 4)\end{array}$ & $\begin{array}{l}60 \%(\mathrm{C} 2) \\
95 \%(\mathrm{C} 4)\end{array}$ & $\begin{array}{l}76 \%(\mathrm{C} 2) \\
98 \%(\mathrm{C} 4)\end{array}$ & $\begin{array}{l}76 \%(C 2), \\
98 \%(C 4)\end{array}$ & $\begin{array}{l}76 \%(\mathrm{C} 2) \\
98 \%(\mathrm{C} 4)\end{array}$ & $\begin{array}{l}76 \%(\mathrm{C} 2) \\
98 \%(\mathrm{C} 4)\end{array}$ & $100 \%(C 4)$ \\
\hline Ketonization: WHSV & $h^{-1}$ & 6 & 4 & 4 & 4 & 4 & 4 & 4 & 6 \\
\hline Ketonization: Per-pass conversion & $\begin{array}{l}\text { wt } \% \text { to desired } \\
\text { products }\end{array}$ & $100 \%$ & $100 \%$ & $100 \%$ & $100 \%$ & $100 \%$ & $100 \%$ & $100 \%$ & $100 \%$ \\
\hline Condensation: WHSV & $h^{-1}$ & 0.5 & $\begin{array}{l}\text { 10-h } \\
\text { residence } \\
\text { time }\end{array}$ & $\begin{array}{l}\text { 10-h } \\
\text { residence } \\
\text { time }\end{array}$ & $\begin{array}{l}\text { 10-h } \\
\text { residence } \\
\text { time }\end{array}$ & $\begin{array}{l}10-\mathrm{h} \\
\text { residence } \\
\text { time }\end{array}$ & $\begin{array}{l}\text { 10-h } \\
\text { residence } \\
\text { time }\end{array}$ & $\begin{array}{l}\text { 10-h } \\
\text { residence } \\
\text { time }\end{array}$ & 15-h batch \\
\hline Condensation: Overall conversion & $\begin{array}{l}\text { wt } \% \text { to desired } \\
\text { products }\end{array}$ & $81 \%$ & $92 \%$ & $92 \%$ & $92 \%$ & $92 \%$ & $92 \%$ & $92 \%$ & $60 \% \mathrm{pp}$ \\
\hline Hydrotreating: WHSV & $h^{-1}$ & 3 & 4.7 & 4.7 & 4.7 & 4.7 & 4.7 & 4.7 & 3 \\
\hline Hydrotreating: Per-pass conversion & $\begin{array}{l}\text { wt } \% \text { to desired } \\
\text { products }\end{array}$ & $100 \%$ & $100 \%$ & $100 \%$ & $100 \%$ & $100 \%$ & $100 \%$ & $100 \%$ & $100 \%$ \\
\hline \multicolumn{10}{|l|}{ Lignin Processing to Coproduct } \\
\hline Solid Deconstruction to Soluble Lignin & wt\% BCD lignin feed & - & - & $85 \%{ }^{\mathrm{e}}$ & - & $85 \%{ }^{\mathrm{e}}$ & - & $85 \%$ e & $53 \%$ \\
\hline Convertible Components in Soluble Lignin & $\begin{array}{l}\text { wt\% of total soluble } \\
\text { lignin }(A P L+B C D)\end{array}$ & - & - & $16 \%$ & - & $16 \%$ & - & $16 \%$ & $98 \%$ \\
\hline Muconic Acid Process Yield from Lignin & g/g soluble lignin & - & - & 0.15 & - & 0.16 & - & 0.16 & 1.59 \\
\hline Muconic Acid Metabolic Yield from Lignin & g/g lignin consumed & - & - & 0.93 & - & 0.93 & - & 0.93 & 0.93 \\
\hline $\begin{array}{l}\text { Overall Carbon Upgrading Efficiency to } \\
\text { Coproduct }^{d}\end{array}$ & $\mathrm{~mol} \%$ & - & - & $4.00 \%$ & - & $4.00 \%$ & - & $4.00 \%$ & $30.10 \%$ \\
\hline Muconic Acid Productivity & $\mathrm{g} / \mathrm{L} / \mathrm{hr}$ & - & - & $0.06(0.53)$ & - & $0.06(0.53)$ & - & $0.06(0.53)$ & 1 \\
\hline Adipic Acid Production & MMlb/yr & - & - & 30 & - & 31 & - & 29 & 187 \\
\hline
\end{tabular}

a 2018-2020 lignin conversion "base" case from actual black liquor/BCD hydrolysate; "high" case (in parentheses) = highest productivity observed to date based on model lignin monomers

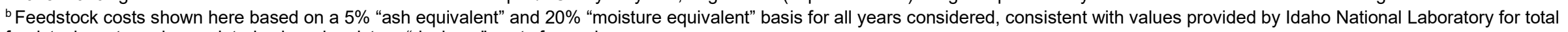
feedstock costs and associated ash and moisture "dockage" costs for each year.

${ }^{\mathrm{C}}$ First number represents sugar conversion to desired product (BDO/acids); values in brackets indicate total sugar utilization (including biomass organism propagation).

${ }^{\mathrm{a}}$ Includes fermentation of all convertible components, product recovery (crystallization) efficiencies, and hydrogenation yields to adipic acid (overall convertible $\mathrm{C}$ to adipic acid)

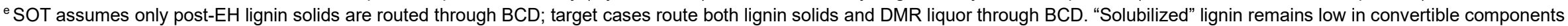
for SOT cases relative to future targets, translating to lower overall carbon efficiency to adipic acid coproduct. 
Table 3 and Figure 2 also show the detailed comparisons between the 2020 SOT scenarios, the 2017-2019 back-cast SOTs, and the future design case targets moving forward to achieving $<\$ 2.50 /$ GGE by 2030 . Moving forward to those future out-year projections, room for further improvement exists to varying degrees across all major processing steps. Namely, DMR pretreatment must move toward reducing water consumption, increasing black liquor concentration, and reducing carbohydrate (xylan/arabinan) losses by incorporating the continuous counter-current alkaline extraction design described in the 2018 design report. With the new two-stage DMR pretreatment approach demonstrated here, biomass deconstruction yields through enzymatic hydrolysis are nearly at their targets for the batch hydrolysis approach (now exceeding the target for xylan conversion and nearly at the target for glucan conversion, at $88 \%$ SOT vs. $90 \%$ targeted using $10 \mathrm{mg} / \mathrm{g}$ enzyme loading). Still, further room for improvement exists regarding development of enzymes more tailored to DMR pretreatment, which will require not only more fundamental understanding of biomass recalcitrance but also continuous collaborations and efforts between national labs and enzyme companies to develop and improve enzyme packages. In the acids case, the $\mathrm{CEH}$ concept must be further developed and eventually integrated into the process to demonstrate efficacy and the ability to at least match, or more ideally exceed, performance for standard batch EH with respect to sugar yields and enzyme loading.

Sugar fermentation and catalytic upgrading performance must also be improved beyond 2020 SOT benchmarks. In the BDO pathway, fermentation yields have already nearly achieved final 2030 goals (on whole slurry hydrolysate), with the exception of arabinose utilization, which must be engineered into the organism, while also nearly doubling the fermentation productivity. However, identifying ways to increase BDO titers will also be of important significance to further reduce MFSPs, either through new fermentation strategies (e.g., hydrolysate clarification and fed-batch fermentation) or through non-distillation BDO concentration strategies (as being investigated under the Separations Consortium). Another area of future work remains in demonstrating fully anaerobic production of BDO rather than minimal oxygen intake via fermentor air overlay (or otherwise better understanding microaerophilic bioreactor design in the TEA models). BDO upgrading yields also have further room for improvement, primarily with respect to the aqueous BDO upgrading step, requiring a doubling in catalyst WHSV and catalyst lifetime.

In the acids pathway, fermentation yields are similarly high for glucose and xylose (meeting or exceeding 2030 targets) but also require more improvement on arabinose utilization, while continuing to optimize operational fed-batch feeding rates to demonstrate the capability to continuously maintain high glucose and xylose conversions, and also improving productivity by roughly a factor of three $(2.0 \mathrm{~g} / \mathrm{L}-\mathrm{hr}$ targets vs. $0.6 \mathrm{~g} / \mathrm{L}-\mathrm{hr}$ SOT basis $)$. Pertractive recovery of acids, while now based on a real hydrolysate fermentation substrate, must also be further optimized to demonstrate the ability to recycle solvents without impacting organism performance over extended time periods. Alternative approaches to pertraction are currently under investigation - for example, based on electrodialysis to recycle the salts, as being investigated by ANL (with NREL TEA support) under the Separations Consortium. Efforts are also ongoing under the ChemCatBio CUBI project to further optimize acids upgrading operations, with the current set of parameters projecting further improvements in ketonization WHSV and further optimized condensation parameters. 
Finally, the largest single area for more substantial improvements is in the lignin-to-coproducts train. As noted above and consistent with the 2018-2019 SOTs, despite the high value of the adipic acid coproduct, the current experimental benchmark data translate to a higher cost to produce the adipic acid than the coproduct revenues it generates, driven most strongly by low bioconversion productivity to muconic acid (translating to large fermentor volumes and costs for this aerobic fermentation step), but also significantly by low deconstruction to soluble/convertible lignin components (as well as no credit yet assumed for productive conversion of either carbohydrates or biomass extractives in black liquor to muconic acid). Relative to 2018/2019 SOT benchmark levels, the lignin train must improve by 2030 to achieve a 17 -fold improvement in productivity (from 0.06 up to $1.0 \mathrm{~g} / \mathrm{L}-\mathrm{hr}$, although productivity on model lignin monomer compounds is considerably higher at $0.5 \mathrm{~g} / \mathrm{L}-\mathrm{hr}$ ) and 10 -fold improvement in overall lignin conversion (from 0.16 to $1.6 \mathrm{~g} / \mathrm{g}$ soluble lignin process yields, translating to overall carbon yield improvement from $4 \%$ to $30 \%$ from convertible carbon through adipic acid), in order to improve overall adipic acid outputs from 31 to roughly $190 \mathrm{MM} \mathrm{lb/yr} \mathrm{in} \mathrm{the} \mathrm{modeled}$ biorefinery. Given that this undoubtedly represents a more substantial required degree of improvement than most other process areas, as well as the fact that performance has not yet been improved for the lignin coproduct train in 2020 beyond initial levels demonstrated in 2018, this generally represents the largest-risk area of the integrated process in ultimately achieving future MFSP goals. As such, in 2020, the Biochemical Analysis project continues to place a primary focus around evaluating potential alternative "contingency strategies" in collaboration with NREL research projects that also may enable MFSP reductions through other processing approaches (based on experimental efforts being undertaken in such areas).

Figure 2 provides a waterfall plot of MFSP cost breakdowns by process area, reflecting all cases listed in Table 3. 


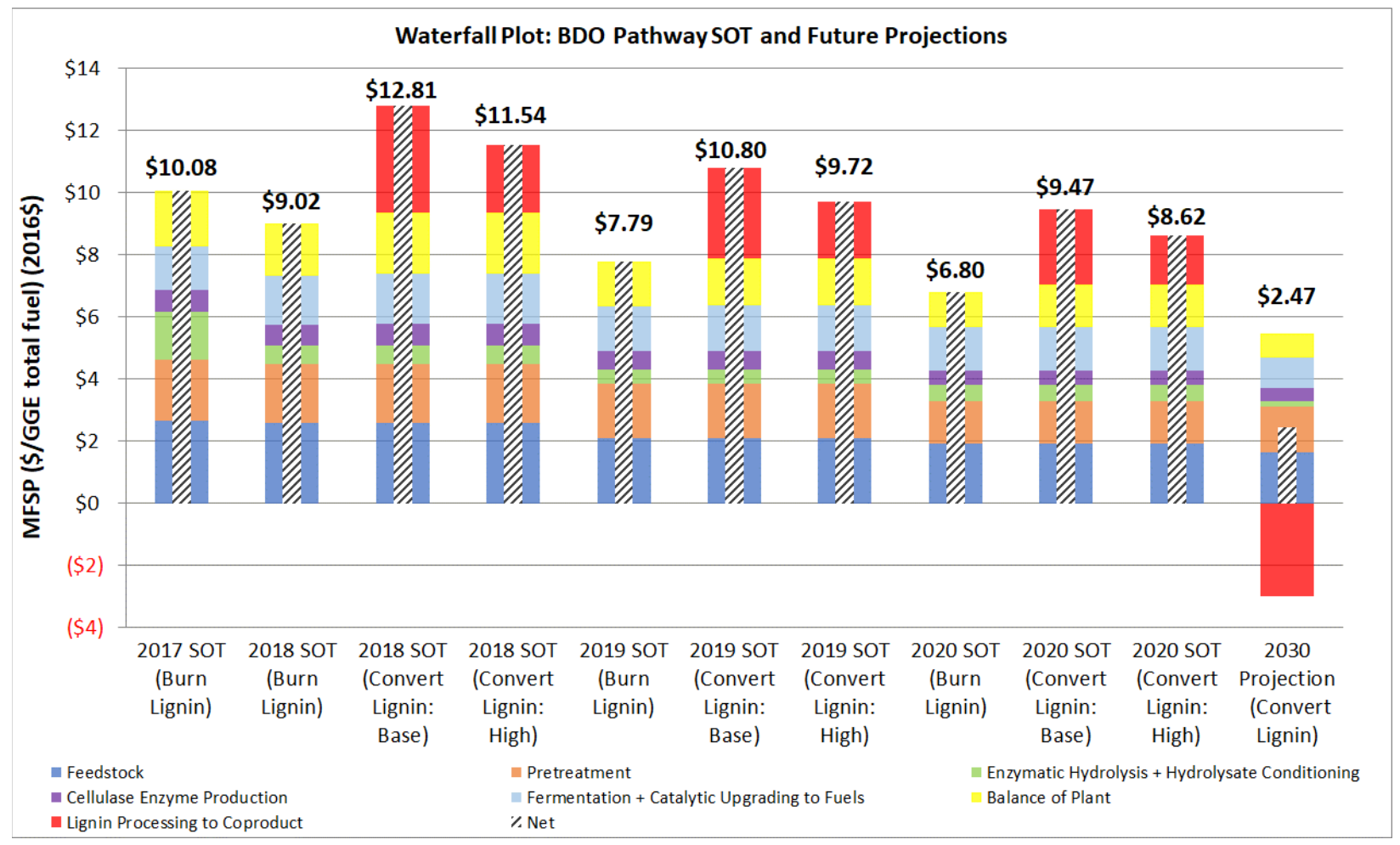

Figure 2(a). Tracking SOT progression from 2017-2020, compared to out-year 2030 projection (BDO pathway)

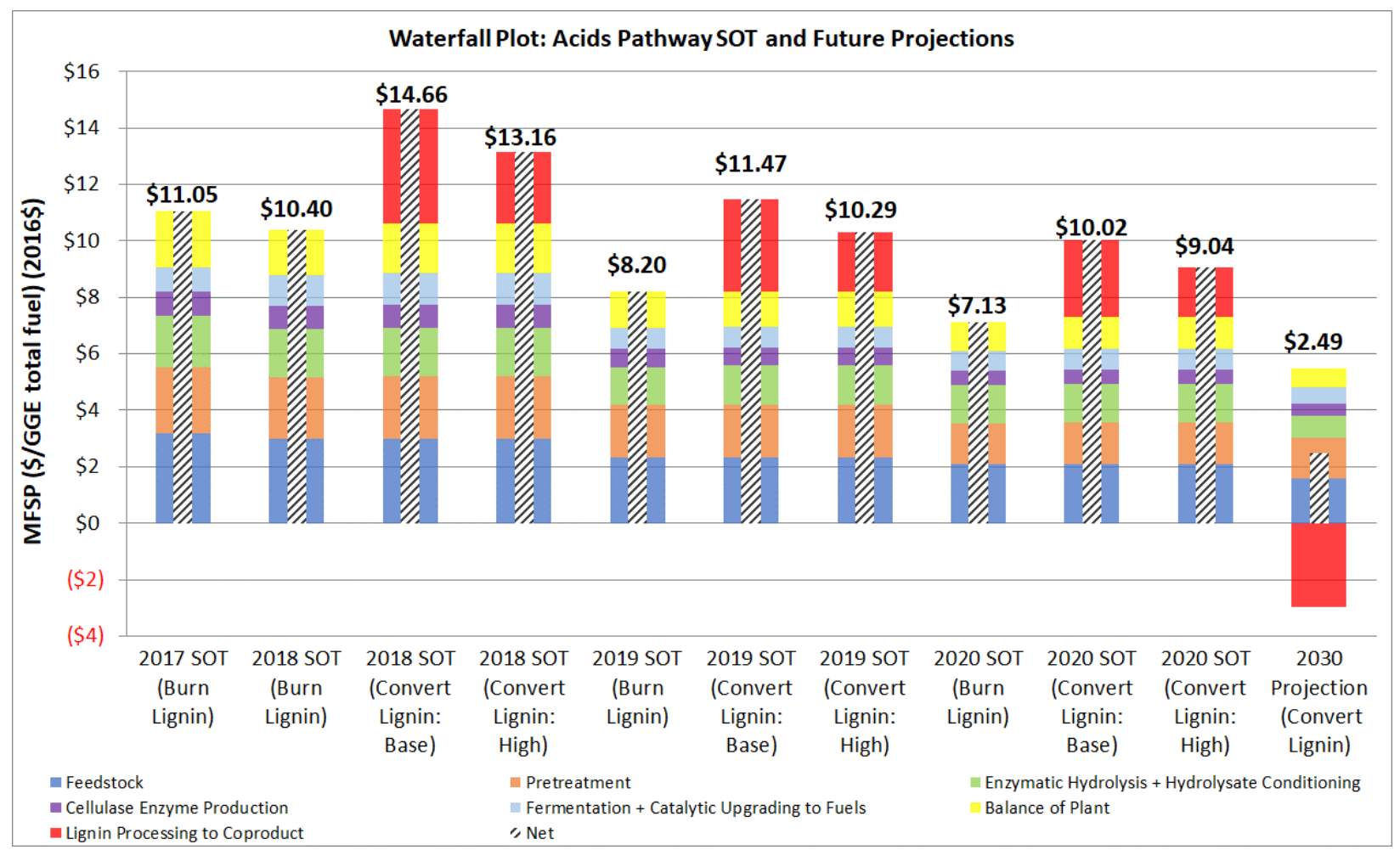

Figure 2(b). Tracking SOT progression from 2017-2020, compared to out-year 2030 projection (acids pathway) 


\section{Sustainability Metric Indicators}

In addition to the TEA results noted above, we also report here on associated sustainability "indicators" attributed to the SOT conversion model scenarios. In keeping with recent Bioenergy Technologies Office (BETO) guidance for all formal LCA sustainability metrics to be handled by ANL to ensure no inconsistencies in such metrics versus NREL-calculated values (i.e., using GREET versus SimaPro), we avoid reporting on LCA parameters such as greenhouse gas emissions or fossil energy consumption in this report (but will provide the input/output inventories to partners at ANL). Instead, Table 4 summarizes key sustainability indicators as may be taken directly from the Aspen Plus process models for all cases presented in Table 3. Namely, this includes mass and carbon yield to fuels, carbon yield to coproducts, facility power and natural gas demands, and water consumption for the conversion process. The process input/output inventories to be furnished to ANL for subsequent LCA supply chain sustainability analysis (SCSA) are summarized in Appendix B.

Both pathways reflect an increase in mass/carbon yield to fuels for the 2020 SOT cases relative to 2019 attributed to improved sugar yields through the biomass deconstruction steps. Both pathways also require a net power import in all cases evaluated due to power demands throughout the facility (driven by mechanical refining pretreatment, MVR sugar evaporation where relevant, and aerobic lignin bioconversion power demands), as well as heat demands diverting steam away from the steam turbine generators. Both cases showed reductions in power demand relative to 2019 in the case of burning lignin, due primarily to lower lignin solubilization from the new two-stage deacetylation approach, leaving more lignin solids routed to the boiler to be burned for heat and power. In all scenarios utilizing natural gas, the natural gas demands have somewhat decreased relative to the 2019 scenarios, also due to higher heat generation in the boiler. Water consumption per GGE fuel also decreased for all cases in 2020 following similar trends in fuel yield improvements. 
Table 4. Sustainability Indicators for 2017-2020 SOT and Future Projection Scenario

\begin{tabular}{|c|c|c|c|c|c|c|c|c|}
\hline & $\begin{array}{l}2017 \\
\text { SOT } \\
\text { (Burn } \\
\text { Lignin) }\end{array}$ & $\begin{array}{c}2018 \\
\text { SOT } \\
\text { (Burn } \\
\text { Lignin) }\end{array}$ & $\begin{array}{c}2018 \\
\text { SOT } \\
\text { Convert } \\
\text { Lignin: } \\
\text { Base } \\
\text { (High) } \\
\end{array}$ & $\begin{array}{c}2019 \\
\text { SOT } \\
\text { (Burn } \\
\text { Lignin) }\end{array}$ & $\begin{array}{c}2019 \\
\text { SOT } \\
\text { Convert } \\
\text { Lignin: } \\
\text { Base } \\
\text { (High) } \\
\end{array}$ & $\begin{array}{l}2020 \\
\text { SOT } \\
\text { (Burn } \\
\text { Lignin) }\end{array}$ & $\begin{array}{c}2020 \\
\text { SOT } \\
\text { Convert } \\
\text { Lignin: } \\
\text { Base } \\
\text { (High) }\end{array}$ & $\begin{array}{c}2030 \\
\text { Projection } \\
\text { (Convert } \\
\text { Lignin) }\end{array}$ \\
\hline \multicolumn{9}{|l|}{ BDO Pathway } \\
\hline $\begin{array}{l}\text { Fuel Yield by Weight of } \\
\text { Biomass (wt } \% \text { of dry biomass) }\end{array}$ & $9.6 \%$ & $9.9 \%$ & $9.9 \%$ & $11.7 \%$ & $11.7 \%$ & $12.6 \%$ & $12.7 \%$ & $13.2 \%$ \\
\hline $\begin{array}{l}\text { Carbon Efficiency to Fuels (\% } \\
\text { feedstock C) }\end{array}$ & $18.2 \%$ & $18.7 \%$ & $18.7 \%$ & $22.1 \%$ & $22.1 \%$ & $23.8 \%$ & $23.9 \%$ & $25.0 \%$ \\
\hline $\begin{array}{l}\text { Carbon Efficiency to Lignin } \\
\text { Coproduct (\% feedstock C) }\end{array}$ & NA & NA & $2.3 \%$ & NA & $2.3 \%$ & NA & $2.2 \%$ & $14.8 \%$ \\
\hline $\begin{array}{l}\text { Net Electricity Import } \\
\text { (kWh/GGE) }\end{array}$ & 12.3 & 5.1 & 14.0 & 5.7 & $\begin{array}{c}12.5 \\
(12.6)\end{array}$ & 4.9 & $\begin{array}{c}11.4 \\
(11.5)\end{array}$ & 10.5 \\
\hline $\begin{array}{l}\text { Net Natural Gas Import } \\
\left.(\text { Btu/GGE [LHV] }]^{a}\right)\end{array}$ & 0 & 0 & $\begin{array}{c}75,284 \\
(76,789) \\
\end{array}$ & 0 & 69,928 & 0 & 60,607 & 14,596 \\
\hline $\begin{array}{l}\text { Water Consumption (gal } \\
\text { water/GGE) }\end{array}$ & 23.4 & 13.9 & $\begin{array}{c}11.3 \\
(11.5) \\
\end{array}$ & 10.9 & 9.2 & 9.3 & 7.8 & 8.9 \\
\hline \multicolumn{9}{|l|}{ Acids Pathway } \\
\hline $\begin{array}{l}\text { Fuel Yield by Weight of } \\
\text { Biomass (wt\% of dry biomass) }\end{array}$ & $8.1 \%$ & $8.6 \%$ & $8.6 \%$ & $10.8 \%$ & $10.8 \%$ & $11.8 \%$ & $11.8 \%$ & $13.8 \%$ \\
\hline $\begin{array}{l}\text { Carbon Efficiency to Fuels (\% } \\
\text { feedstock C) }\end{array}$ & $15.5 \%$ & $16.3 \%$ & $16.3 \%$ & $20.6 \%$ & $20.6 \%$ & $22.5 \%$ & $22.4 \%$ & $26.2 \%$ \\
\hline $\begin{array}{l}\text { Carbon Efficiency to Lignin } \\
\text { Coproduct (\% feedstock C) }\end{array}$ & NA & NA & $2.3 \%$ & NA & $2.3 \%$ & NA & $2.2 \%$ & $14.4 \%$ \\
\hline $\begin{array}{l}\text { Net Electricity Import } \\
(\mathrm{kWh} / \mathrm{GGE})\end{array}$ & 5.8 & 1.3 & $\begin{array}{c}21.5 \\
(21.6) \\
\end{array}$ & 2.8 & $\begin{array}{c}17.4 \\
(17.6) \\
\end{array}$ & 2.2 & $\begin{array}{c}15.5 \\
(15.6) \\
\end{array}$ & 10.7 \\
\hline $\begin{array}{l}\text { Net Natural Gas Import } \\
\text { (Btu/GGE [LHV]) }\end{array}$ & 0 & 15,790 & 15,790 & 11,803 & 11,803 & 11,064 & 11,035 & 9,055 \\
\hline $\begin{array}{l}\text { Water Consumption (gal } \\
\text { water/GGE) }\end{array}$ & 30.7 & 36.0 & $\begin{array}{l}26.0 \\
(26.1)\end{array}$ & 27.7 & 20.0 & 24.7 & 17.9 & 13.5 \\
\hline
\end{tabular}

${ }^{a}$ Lower heating value 


\section{Concluding Remarks}

The work presented here provides a re-benchmarking of NREL's Biochemical Platform efforts in moving toward future design case goals. Based on data availability for 2020 experimental work on integrated hydrolysate processing, the 2020 SOT considers two bioconversion pathways for hydrocarbon fuel production, namely BDO and carboxylic acids. Biomass deconstruction efforts presently reflect $88 \%$ glucan conversion, $>93 \%$ xylan conversion, and $91 \%$ arabinan conversion to monomeric sugars through saccharification at $10 \mathrm{mg} / \mathrm{g}$ total enzyme loading, enabled by a new two-stage DMR pretreatment approach employed in 2020 making use of sodium carbonate to reduce more costly sodium hydroxide usage (also expected to yield notable LCA improvements). Catalytic upgrading performance for both fuel pathways was not seen to improve over 2019 levels, and thus 2019 SOT benchmarks were maintained for those operations, although those prior data were already quite favorable, utilizing over $95 \%$ of glucose and $89 \%$ of xylose sugars at fermentation process yields approaching or exceeding final design case targets (albeit at lower productivities relative to final targets), and catalytic conversions of $100 \%$ to fuel products across all steps that were experimentally demonstrated (albeit at lower space velocities in some steps than final targets). The resulting 2020 SOT benchmark MFSPs are estimated to be

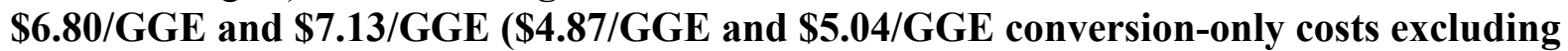
feedstock contributions at \$80/ton) in 2016 dollars based on combustion of all lignin and residual solids for the BDO and acids pathways, respectively. Relative to the previous 2019 SOT basis, this translates to an improvement of \$0.99/GGE (13\%) and \$1.07/GGE (13\%) in overall MFSPs for the two respective pathways.

Alternative SOT scenarios were also evaluated inclusive of lignin conversion to coproducts, with 2020 SOT MFSP estimates of $\$ \mathbf{9 . 4 7 / G G E}$ and $\mathbf{\$ 1 0 . 0 2}$ /GGE for "base case" lignin conversion performance on biomass hydrolysate (BDO and acids pathways, respectively); this would hypothetically reduce to \$8.62/GGE and \$9.04/GGE for "high" lignin conversion performance as observed for model lignin monomers. These results maintain that the lignin-tocoproduct train is not yet economically profitable relative to burning the lignin, given higher costs for producing the adipic acid coproduct than the amount of coproduct revenue generated (attributed in turn to low lignin deconstruction/conversion yields and fermentation productivities observed to date). Performance parameters for the lignin coproduct train were generally not shown to be improved in 2020 beyond initial demonstration levels in the 2018 SOT (also reflected consistently in the 2019 SOT). As an alternative sensitivity scenario for the acids pathway, when reflecting experimentally measured values for xylose fermentation to acids ( $68 \%$ to product in the 2019 SOT) in place of the performance asserted to be realistic for an optimized sugar feeding/pertraction operational approach (95\% to product), the acids pathway MFSPs

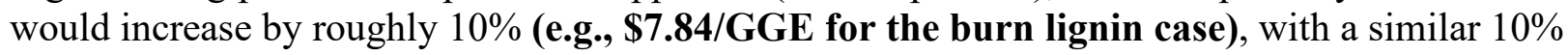
reduction in fuel yield.

Analysis of sustainability metric indicators from the Aspen SOT conversion models demonstrates $\mathrm{BDO}$ fuel yields of $12.6 \%$ by weight or $23.8 \%$ by carbon retention relative to biomass feedstock, along with $2.2 \%$ carbon yields to adipic acid coproduct in the "convert lignin" scenarios. Fuel yields are slightly lower for the acids case at $11.8 \%$ by weight or $22.5 \%$ by carbon utilization, with the same $2.2 \%$ carbon yield basis to adipic acid. Net power imports are calculated as $4.9 \mathrm{kWh} / \mathrm{GGE}$ for the $\mathrm{BDO}$ case or $2.2 \mathrm{kWh} / \mathrm{GGE}$ for the acids case in the "burn lignin" scenario, increasing to 11.4 and $15.5 \mathrm{kWh} / \mathrm{GGE}$, respectively, in the "convert 
lignin" scenario (due to substantial power demands for aerobic lignin bioconversion at low fermentation productivities). Approximately $61,000 \mathrm{Btu} / \mathrm{GGE}$ of supplemental natural gas is required for the 2020 SOT BDO cases including lignin conversion, but none is required for the "burn lignin" scenario, while for the acids case, roughly 11,000 Btu/GGE of natural gas is required in all 2020 SOT cases as a means to provide necessary utility trim heating for catalytic upgrading process temperature demands. Finally, water consumption is estimated at $9.3 \mathrm{gal} / \mathrm{GGE}$ for the BDO "burn lignin" case, and roughly $7.8 \mathrm{gal} / \mathrm{GGE}$ for the BDO "convert lignin" case. Water consumption is higher at $24.7 \mathrm{gal} / \mathrm{GGE}$ in the acids "burn lignin" case, reducing to 17.9 gal/GGE in the "convert lignin" case, driven in part by still requiring the hydrolysate solid/liquid separation and water wash step.

Moving forward, further room for improvement exists to reduce costs to 2030 goals. Namely, while deconstruction was the primary area of improvement in the 2020 SOT, achieving sugar yields approaching or exceeding final 2030 targets with reduced sodium hydroxide loadings (with a trade-off of new sodium carbonate addition), the deacetylation step may be further optimized by increasing liquor concentrations and reducing carbohydrate losses into the soluble liquor fraction (e.g., through continuous counter-current alkaline extraction rather than batch deacetylation. Deconstruction improvements also include integrating and demonstrating continuous enzymatic hydrolysis into the process as a means to further reduce costs in the acids pathway. Additionally, fuel-train fermentation and catalytic upgrading yields, as well as recoveries of intermediate products, must also be further improved, in line with final design case targets (although many associated parameters are already beginning to approach or in some cases exceed final targets). A key operation undergoing continued R\&D focus and optimization in the Separations Consortium for the acids pathway is around low-cost recovery of the intermediate acids utilizing continuous pertraction at high recovery efficiencies (including better understanding scale-up implications on design and cost details) or alternative approaches to avoid significant fresh caustic/acid demands - or most ideally achieving low-pH fermentation without the need for any acids isolation operations. Finally, more significant improvements are required in the lignin coproduct train in order to first break even and ultimately lower MFSPs toward future 2030 targets. This primarily centers around increasing lignin deconstruction to convertible monomers, incorporating the capability to utilize other components such as carbohydrates and extractives, and improving bioconversion productivity to muconic acid (subsequently upgraded to adipic acid via mild hydrogenation). 


\section{References}

NREL milestone reports cited below cannot be accessed outside of NREL and DOE. Readers may contact the authors of those reports to determine if this information has been made public since publication of this report.

[1] Aspen Technology Inc. 2017. "Aspen Plus V10."

https://www.aspentech.com/en/products/engineering/aspen-plus.

[2] R. E. Davis, N. J. Grundl, L. Tao, M. J. Biddy, E. C. D. Tan, G. T. Beckham, D. Humbird, D. N. Thompson, and M. S. Roni. 2018. Process Design and Economics for the Conversion of Lignocellulosic Biomass to Hydrocarbon Fuels and Coproducts: 2018 Biochemical Design Case Update; Biochemical Deconstruction and Conversion of Biomass to Fuels and Products via Integrated Biorefinery Pathways. Golden, CO: National Renewable Energy Lab. https://www.nrel.gov/docs/fy19osti/71949.pdf.

[3] R. Davis, M. Biddy, L. Tao, and N. Grundl. 2018. "FY18 Q2 Go/No Go - Pathway DownSelect for FY18 Design Report. NREL Milestone Report.

[4] R. Davis, L. Tao, E. C. D. Tan, M. Biddy, G. T. Beckham, C. Scarlata, J. Jacobson, K. Cafferty, J. Ross, J. Lukas, D. Knorr, and P. Schoen. 2013. Process Design and Economics for the Conversion of Lignocellulosic Biomass to Hydrocarbons: Dilute-Acid and Enzymatic Deconstruction of Biomass to Sugars and Biological Conversion of Sugars to Hydrocarbons. Golden, CO: National Renewable Energy Laboratory. http://www.nrel.gov/docs/fy14osti/60223.pdf.

[5] X. Chen, E. Kuhn, N. Nagle, R. Nelson, L. Tao, N. Crawford, and M. Tucker. 2018. "Recycling of Dilute Deacetylation Black Liquor to Enable Efficient Recovery and Reuse of Spent Chemicals and Biomass Pretreatment Waste." Frontiers in Energy Research 6: 51. https://doi.org/10.3389/fenrg.2018.00051.

[6] R. Davis, A. Bartling, and L. Tao. 2020. Biochemical Conversion of Lignocellulosic Biomass to Hydrocarbon Fuels and Products: 2019 State of Technology and Future Research. Golden, CO: National Renewable Energy Laboratory. https://www.nrel.gov/docs/fy20osti/76567.pdf.

[7] H. Cai, L. Ou, M. Wang, E. Tan, R. Davis, A. Dutta, L. Tao, D. Hartley, M. Roni, D. Thompson, L. Snowden-Swan, and Y. Zhu. 2020. Supply Chain Sustainability Analysis of Renewable Hydrocarbon Fuels via Indirect Liquefaction, Ex Situ Catalytic Fast Pyrolysis, Hydrothermal Liquefaction, Combined Algal Processing, and Biochemical Conversion: Update of the 2019 State-of-Technology Cases. Lemont, IL: Argonne National Laboratory. https://greet.es.anl.gov/files/renewable ho 2019.

[8] X. Chen, A. Mittal, and N. Nagle. 2020. "Achieve over $88 \%$ monomeric sugar yields at an enzyme loading of $10 \mathrm{mg} / \mathrm{g}$ of cellulose and an initial solids loading of $22.5 \mathrm{wt} \%$ from a recalcitrant corn stover feedstock deacetylated at $70 \mathrm{~kg} \mathrm{NaOH} /$ tonne of biomass (down from 80) using the ozone assisted DMR process option." NREL Milestone Report. 
[9] D. Humbird, R. Davis, L. Tao, C. Kinchin, D. Hsu, A. Aden, P. Schoen, J. Lukas, B. Olthof, M. Worley, D. Sexton, and D. Dudgeon. 2011. Process Design and Economics for Biochemical Conversion of Lignocellulosic Biomass to Ethanol. Golden, CO: National Renewable Energy Laboratory. http://www.nrel.gov/docs/fy11osti/47764.pdf.

[10] R. Davis, L. Tao, C. Scarlata, E. C. D. Tan, J. Ross, J. Lukas, and D. Sexton. 2015. Process Design and Economics for the Conversion of Lignocellulosic Biomass to Hydrocarbons: Dilute-Acid and Enzymatic Deconstruction of Biomass to Sugars and Catalytic Conversion of Sugars to Hydrocarbons. Golden, CO: National Renewable Energy Laboratory. http://www.nrel.gov/docs/fy15osti/62498.pdf.

[11] R. Davis, M. Biddy, L. Tao, N. Grundl, G. Beckham, N. Dowe, M. Himmel, and M. Zhang. 2016. "TEA Identification of Most Promising Options for 2022 Targets." NREL milestone report.

[12] N. A. Huq, X. Huo, G. R. Hafenstine, S. M. Tifft, J. Stunkel, E. D. Christensen, G. M. Fioroni, et al. 2019. "Performance-Advantaged Ether Diesel Bioblendstock Production by a priori Design." Proceedings of the National Academy of Sciences 116 (52): 26421-26430.

[13] G.R. Hafenstine, N.A. Huq, D.R. Conklin, M.R. Wiatrowski, X. Huo, Q. Guo, K.A. Unocic, and D.R. Vardon. 2020. "Single-Phase Catalysis for Reductive Etherification of Diesel Bioblendstocks." Green Chemistry 22: 4463-4472.

[14] R. Davis, N. Grundl, and L. Tao. 2018. "FY18 State of Technology Report." NREL milestone report. 


\section{Appendix A. TEA Summary Sheets for 2020 SOT Benchmark Models (2016 dollars)}

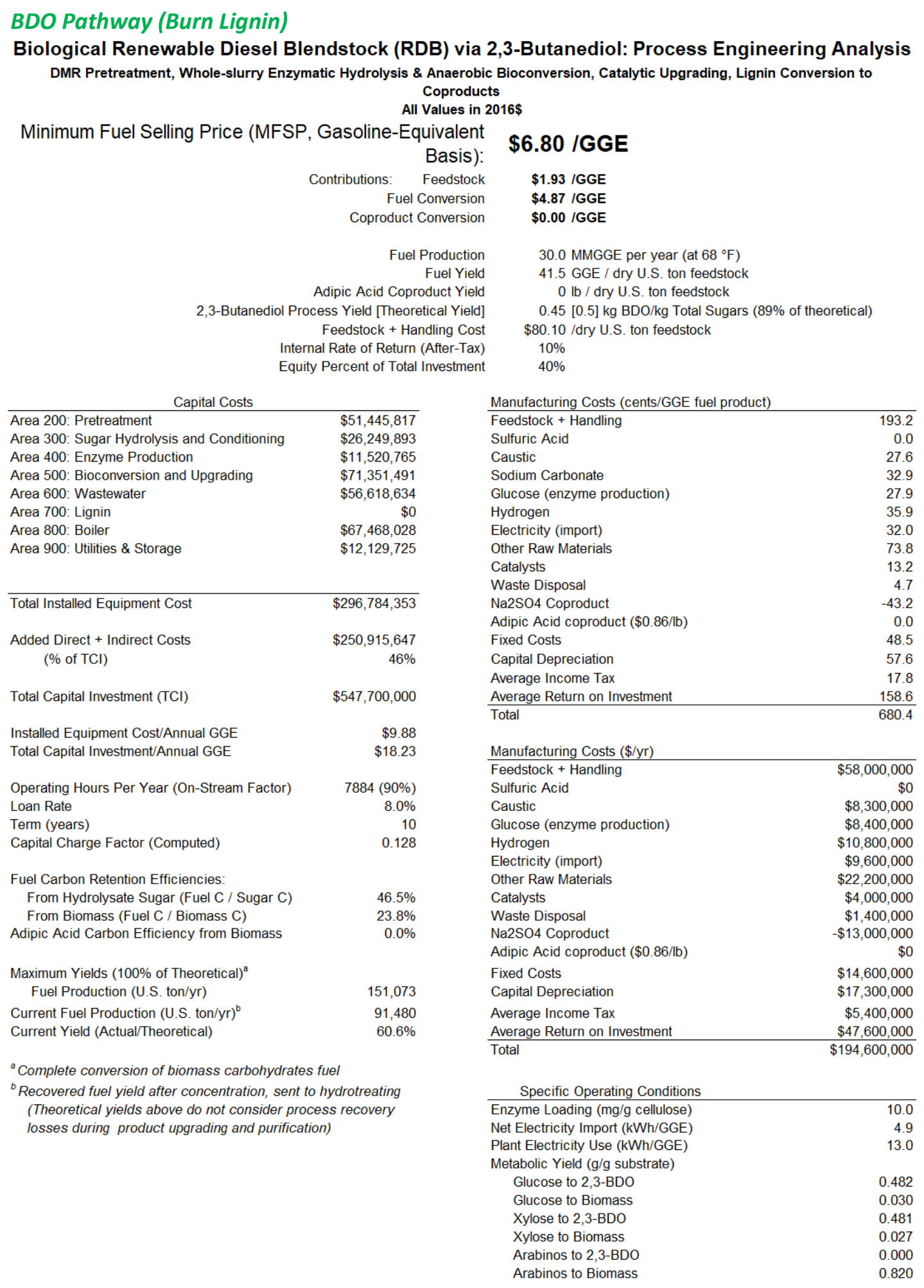


BDO Pathway (Convert Lignin - "Base")

Biological Renewable Diesel Blendstock (RDB) via 2,3-Butanediol: Process Engineering Analysis DMR Pretreatment, Whole-slurry Enzymatic Hydrolysis \& Anaerobic Bioconversion, Catalytic Upgrading, Lignin Conversion to Coproducts

All Values in $2016 \$$

Minimum Fuel Selling Price (MFSP, Gasoline-Equivalent

Basis):

Contributions: Feedstock Fuel Conversion

Coproduct Conversion

Fuel Production

Fuel Yield

Adipic Acid Coproduct Yield 2,3-Butanediol Process Yield [Theoretical Yield]

Feedstock + Handling Cost Internal Rate of Return (After-Tax) Equity Percent of Total Investment

\begin{tabular}{|c|c|}
\hline \multicolumn{2}{|l|}{ Capital Costs } \\
\hline Area 200: Pretreatment & $\$ 51,390,153$ \\
\hline Area 300: Sugar Hydrolysis and Conditioning & $\$ 26,249,944$ \\
\hline Area 400: Enzyme Production & $\$ 11,520,765$ \\
\hline Area 500: Bioconversion and Upgrading & $\$ 71,371,195$ \\
\hline Area 600: Wastewater & $\$ 58,529,395$ \\
\hline Area 700: Lignin & $\$ 263,033,875$ \\
\hline Area 800: Boiler & $\$ 51,476,621$ \\
\hline Area 900: Utilities \& Storage & $\$ 13,542,956$ \\
\hline Total Installed Equipment Cost & $\$ 547,114,903$ \\
\hline Added Direct + Indirect Costs & $\$ 498,385,097$ \\
\hline (\% of $\mathrm{TCl})$ & $48 \%$ \\
\hline Total Capital Investment (TCl) & $\$ 1,045,500,000$ \\
\hline Installed Equipment Cost/Annual GGE & $\$ 18.15$ \\
\hline Total Capital Investment/Annual GGE & $\$ 34.69$ \\
\hline Operating Hours Per Year (On-Stream Factor) & $7884(90 \%)$ \\
\hline Loan Rate & $8.0 \%$ \\
\hline Term (years) & 10 \\
\hline Capital Charge Factor (Computed) & 0.127 \\
\hline Fuel Carbon Retention Efficiencies: & \\
\hline From Hydrolysate Sugar (Fuel C / Sugar C) & $46.7 \%$ \\
\hline From Biomass (Fuel C / Biomass C) & $23.9 \%$ \\
\hline Adipic Acid Carbon Efficiency from Biomass & $2.2 \%$ \\
\hline Maximum Yields $(100 \% \text { of Theoretical })^{\mathrm{a}}$ & \\
\hline Fuel Production (U.S. ton/yr) & 151,073 \\
\hline Current Fuel Production (U.S. ton/yr) ${ }^{\mathrm{b}}$ & 91,772 \\
\hline Current Yield (Actual/Theoretical) & $60.7 \%$ \\
\hline${ }^{a}$ Complete conversion of biomass carbohydra & fuel \\
\hline $\begin{array}{r}{ }^{b} \text { Recovered fuel yield after concentration, sen } \\
\text { (Theoretical yields above do not consider p } \\
\text { losses during product upgrading and purific }\end{array}$ & $\begin{array}{l}\text { hydrotreating } \\
\text { ess recovery } \\
\text { on) }\end{array}$ \\
\hline
\end{tabular}

\section{$\$ 9.47$ /GGE}

$\$ 1.93$ /GGE

$\$ 5.14 / G G E$

$\$ 2.40 / G G E$

30.1 MMGGE per year (at $68^{\circ} \mathrm{F}$ )

41.6 GGE / dry U.S. ton feedstock

$39 \mathrm{lb} /$ dry U.S. ton feedstock

0.45 [0.5] kg BDO/kg Total Sugars (89\% of theoretical)

$\$ 80.10$ /dry U.S. ton feedstock

$10 \%$

$40 \%$

Manufacturing Costs (cents/GGE fuel product)

\begin{tabular}{lr}
\hline Feedstock + Handling & 192.5 \\
Sulfuric Acid & 28.6 \\
Caustic & 52.1 \\
Sodium Carbonate & 32.8 \\
Glucose (enzyme production) & 27.8 \\
Hydrogen & 41.7 \\
Electricity (import) & 76.3 \\
Other Raw Materials & 88.6 \\
Catalysts & 13.8 \\
Waste Disposal & 4.8 \\
Na2SO4 Coproduct & -58.6 \\
Adipic Acid coproduct $(\$ 0.86 / \mathrm{lb})$ & -81.0 \\
Fixed Costs & 85.5 \\
Capital Depreciation & 109.8 \\
Average Income Tax & 33.1 \\
Average Return on Investment & 299.3 \\
\hline Total & 947.1 \\
\end{tabular}

Manufacturing Costs $(\$ / y r)$

Feedstock + Handling $\$ 58,000,000$

Sulfuric Acid $\$ \$ 8,600,000$

Caustic $\$ \$ 15,700,000$

Glucose (enzyme production) $\quad \$ 8,400,000$

Hydrogen $\$ \$ 12,600,000$

Electricity (import) $\$ \$ 23,000,000$

Other Raw Materials $\quad \$ 26,700,000$

Catalysts $\$ \$ 4,200,000$

Waste Disposal $\$ \$ 1,500,000$

Na2SO4 Coproduct $\quad-\$ 17,700,000$

Adipic Acid coproduct $(\$ 0.86 / \mathrm{lb}) \quad-\$ 24,400,000$

Fixed Costs $\$ 25,800,000$

Capital Depreciation $\$ 33,100,000$

Average Income Tax $\$ \$ 10,000,000$

Average Return on Investment $\$ \$ 90,200,000$

Total $\$ 275,700,000$

Specific Operating Conditions

\begin{tabular}{ll}
\hline Enzyme Loading (mg/g cellulose) & 10.0 \\
Net Electricity Import (kWh/GGE) & 11.4 \\
Plant Electricity Use (kWh/GGE) & 14.2 \\
Metabolic Yield (g/g substrate) & \\
$\quad$ Glucose to 2,3-BDO & 0.482 \\
Glucose to Biomass & 0.030 \\
Xylose to 2,3-BDO & 0.481 \\
Xylose to Biomass & 0.027 \\
Arabinos to 2,3-BDO & 0.000 \\
Arabinos to Biomass & 0.818
\end{tabular}


BDO Pathway (Convert Lignin - "High")

Biological Renewable Diesel Blendstock (RDB) via 2,3-Butanediol: Process Engineering Analysis DMR Pretreatment, Whole-slurry Enzymatic Hydrolysis \& Anaerobic Bioconversion, Catalytic Upgrading, Lignin Conversion to Coproducts

\section{All Values in 2016\$}

Minimum Fuel Selling Price (MFSP, Gasoline-Equivalent

Basis):

Contributions: Feedstock Fuel Conversion

Coproduct Conversion

Fuel Production

Fuel Yield

Adipic Acid Coproduct Yield 2,3-Butanediol Process Yield [Theoretical Yield]

Feedstock + Handling Cost Internal Rate of Return (After-Tax) Equity Percent of Total Investment

\begin{tabular}{lr}
\multicolumn{2}{c}{ Capital Costs } \\
\hline Area 200: Pretreatment & $\$ 51,390,153$ \\
Area 300: Sugar Hydrolysis and Conditioning & $\$ 26,249,944$ \\
Area 400: Enzyme Production & $\$ 11,520,765$ \\
Area 500: Bioconversion and Upgrading & $\$ 71,371,195$ \\
Area 600: Wastewater & $\$ 58,525,768$ \\
Area 700: Lignin & $\$ 173,932,641$ \\
Area 800: Boiler & $\$ 51,474,315$ \\
Area 900: Utilities \& Storage & $\$ 13,547,465$
\end{tabular}

Total Installed Equipment Cost

$\$ 458,012,246$

Added Direct + Indirect Costs

( $\%$ of $\mathrm{TCl})$

$\$ 411,587,754$

$47 \%$

Total Capital Investment (TCl)

$\$ 869,600,000$

Installed Equipment Cost/Annual GGE

$\$ 15.20$

Total Capital Investment/Annual GGE

$\$ 28.85$

Operating Hours Per Year (On-Stream Factor)

Loan Rate

Term (years)

Capital Charge Factor (Computed)

Fuel Carbon Retention Efficiencies:

From Hydrolysate Sugar (Fuel C / Sugar C)

From Biomass (Fuel C / Biomass C)

Adipic Acid Carbon Efficiency from Biomass

Maximum Yields (100\% of Theoretical $)^{\mathrm{a}}$

Fuel Production (U.S. ton/yr)

Current Fuel Production (U.S. ton/yr) ${ }^{\mathrm{b}}$

Current Yield (Actual/Theoretical)

$7884(90 \%)$

$8.0 \%$

10

0.128

$46.7 \%$

$23.9 \%$

$2.2 \%$

151,073

91,772

$60.7 \%$

${ }^{a}$ Complete conversion of biomass carbohydrates fuel

${ }^{b}$ Recovered fuel yield after concentration, sent to hydrotreating (Theoretical yields above do not consider process recovery losses during product upgrading and purification)

\section{$\$ 8.62$ /GGE}

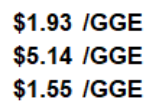

$\$ 1.55$ /GGE

30.1 MMGGE per year (at $68^{\circ} \mathrm{F}$ )

41.6 GGE / dry U.S. ton feedstock

$39 \mathrm{lb} /$ dry U.S. ton feedstock

0.45 [0.5] kg BDO/kg Total Sugars ( $89 \%$ of theoretical)

$\$ 80.10$ /dry U.S. ton feedstock

$10 \%$

$40 \%$

Manufacturing Costs (cents/GGE fuel product)

Feedstock + Handling $\quad 192.5$

$\begin{array}{lr}\text { Sulfuric Acid } & 28.6\end{array}$

Caustic $\quad 52.1$

Sodium Carbonate $\quad 32.8$

Glucose (enzyme production) $\quad 27.8$

Hydrogen $\quad 41.7$

Electricity (import) $\quad 77.1$

Other Raw Materials $\quad 88.6$

Catalysts $\quad 13.8$

Waste Disposal $\quad 4.8$

$\mathrm{Na} 2 \mathrm{SO} 4$ Coproduct $\quad-58.6$

Adipic Acid coproduct $(\$ 0.86 / \mathrm{lb}) \quad-80.9$

$\begin{array}{ll}\text { Fixed Costs } & 72.7\end{array}$

Capital Depreciation $\quad 91.2$

Average Income Tax $\quad 27.7$

\begin{tabular}{ll} 
Average Return on Investment & 250.1 \\
\hline Total & 862.1
\end{tabular}

Manufacturing Costs $(\$ / y r)$

Feedstock + Handling $\$ 58,000,000$

$\begin{array}{lr}\text { Sulfuric Acid } & \$ 8,600,000\end{array}$

Caustic $\$ 15,700,000$

Glucose (enzyme production) $\quad \$ 8,400,000$

Hydrogen $\$ 12,600,000$

Electricity (import) $\$ 23,200,000$

Other Raw Materials $\$ 26,700,000$

Catalysts $\$ \$, 200,000$

Waste Disposal $\$ 1,500,000$

Na2SO4 Coproduct $\quad-\$ 17,700,000$

Adipic Acid coproduct $(\$ 0.86 / \mathrm{lb}) \quad-\$ 24,400,000$

Fixed Costs $\$ 21,900,000$

Capital Depreciation $\$ 27,500,000$

Average Income Tax $\$ \$ 8,400,000$

Average Return on Investment $\$ \$ 75,400,000$

$\begin{array}{lr}\$ 250,000,000 & \end{array}$

Specific Operating Conditions

Enzyme Loading (mg/g cellulose) 10.0

Net Electricity Import (kWh/GGE) $\quad 11.5$

Plant Electricity Use (kWh/GGE) 14.3

Metabolic Yield ( $\mathrm{g} / \mathrm{g}$ substrate)

Glucose to 2,3-BDO 0.482

Glucose to Biomass $\quad 0.030$

Xylose to 2,3-BDO $\quad 0.481$

Xylose to Biomass $\quad 0.027$

Arabinos to 2,3-BDO $\quad 0.000$

Arabinos to Biomass $\quad 0.818$ 


\section{Acids Pathway (Burn Lignin)}

Biological Renewable Diesel Blendstock (RDB) via Butyric Acids: Process Engineering Analysis DMR Pretreatment, Batch Enzymatic Hydrolysis, Hydrolysate Clarification, Anaerobic Bioconversion, Catalytic Upgrading, Lignin Combustion

All Values in $2016 \$$

Minimum Fuel Selling Price (MFSP, Gasoline-Equivalent

Basis):

Contributions: Feedstock Fuel Conversion

Coproduct Conversion

Fuel Production

Fuel Yield

Adipic Acid Coproduct Yield Butyric Acid Process Yield [Theoretical Yield]

Feedstock + Handling Cost Internal Rate of Return (After-Tax) Equity Percent of Total Investment

\section{$\$ 7.13$ /GGE}

$\$ 2.08 / G G E$

$\$ 5.04 / G G E$

$\$ 0.00 / G G E$

27.9 MMGGE per year (at $68^{\circ} \mathrm{F}$ )

38.5 GGE / dry U.S. ton feedstock

$0 \mathrm{lb} / \mathrm{dry}$ U.S. ton feedstock

0.44 [0.49] kg Acid/kg Total Sugars (89\% of theoretical) $\$ 80.10 /$ dry U.S. ton feedstock

$10 \%$

$40 \%$

\begin{tabular}{lr}
\multicolumn{2}{c}{ Capital Costs } \\
\hline Area 200: Pretreatment & $\$ 51,445,817$ \\
Area 300: Sugar Hydrolysis and Conditioning & $\$ 82,903,853$ \\
Area 400: Enzyme Production & $\$ 11,520,765$ \\
Area 500: Bioconversion and Upgrading & $\$ 49,013,154$ \\
Area 600: Wastewater & $\$ 60,270,174$ \\
Area 700: Lignin & $\$ 0$ \\
Area 800: Boiler & $\$ 69,608,234$ \\
Area 900: Utilities \& Storage & $\$ 11,776,742$
\end{tabular}

Total Installed Equipment Cost

$\$ 336,538,739$

Added Direct + Indirect Costs

(\% of $\mathrm{TCl}$ )

$\$ 287,961,261$

$46 \%$

Total Capital Investment (TCl)

$\$ 624,500,000$

Installed Equipment Cost/Annual GGE

$\$ 12.08$

Total Capital Investment/Annual GGE

$\$ 22.41$

Operating Hours Per Year (On-Stream Factor)

Loan Rate

Term (years)

Capital Charge Factor (Computed)

Fuel Carbon Retention Efficiencies:

From Hydrolysate Sugar (Fuel C / Sugar C) $\quad 46.2 \%$

From Biomass (Fuel C / Biomass C) $22.5 \%$

Adipic Acid Carbon Efficiency from Biomass $\quad 0.0 \%$

Maximum Yields (100\% of Theoretical) ${ }^{\mathrm{a}}$

Fuel Production (U.S. ton/yr)

Current Fuel Production (U.S. ton/yr) ${ }^{\mathrm{b}}$

Current Yield (Actual/Theoretical)

128,798

85,467

$66.4 \%$

${ }^{a}$ Complete conversion of biomass carbohydrates fuel

${ }^{b}$ Recovered fuel yield after concentration, sent to hydrotreating (Theoretical yields above do not consider process recovery losses during product upgrading and purification)
Manufacturing Costs (cents/GGE fuel product)

\begin{tabular}{lr}
\hline Feedstock + Handling & 208.2 \\
Sulfuric Acid & 0.0 \\
Caustic & 29.7 \\
Sodium Carbonate & 35.5 \\
Glucose (enzyme production) & 30.0 \\
Hydrogen & 0.0 \\
Electricity (import) & 13.5 \\
Other Raw Materials & 90.3 \\
Catalysts & 2.3 \\
Waste Disposal & 5.1 \\
Na2SO4 Coproduct & -45.4 \\
Adipic Acid coproduct (\$0.86/lb) & 0.0 \\
Fixed Costs & 57.8 \\
Capital Depreciation & 71.1 \\
Average Income Tax & 21.6 \\
Average Return on Investment & 192.8 \\
\hline Total & 712.6
\end{tabular}

Total

192.8

Manufacturing Costs $(\$ / \mathrm{yr})$

Feedstock + Handling $\$ 58,000,000$

Sulfuric Acid

Caustic $\$ 8,300,000$

Glucose (enzyme production) $\quad \$ 8,400,000$

Hydrogen $\$ 0$

Electricity (import) $\$ \$ 3,800,000$

Other Raw Materials $\$ \$ 25,200,000$

Catalysts $\$ 600,000$

Waste Disposal $\$ 1,400,000$

Na2SO4 Coproduct $\quad-\$ 12,700,000$

Adipic Acid coproduct $(\$ 0.86 / \mathrm{lb}) \quad \$ 0$

Fixed Costs $\$ \$ 16,100,000$

Capital Depreciation $\$ \$ 19,800,000$

Average Income Tax $\$ \$ 6,000,000$

Average Return on Investment $\$ \$ 53,700,000$

Total

$\$ 188,600,000$

Specific Operating Conditions

\begin{tabular}{lr}
\hline Enzyme Loading (mg/g cellulose) & 10.0 \\
Net Electricity Import (kWh/GGE) & 2.2 \\
Plant Electricity Use (kWh/GGE) & 15.7 \\
Metabolic Yield (g/g substrate) & \\
$\quad$ Glucose to Butyric & 0.46 \\
Glucose to Biomass & 0.02 \\
$\quad$ Xylose to Butyric & 0.46 \\
$\quad$ Xylose to Biomass & 0.02 \\
Arabinos to Butyric & 0.11 \\
Arabinos to Biomass & 0.07
\end{tabular}




\section{Acids Pathway (Convert Lignin - "Base") \\ Biological Renewable Diesel Blendstock (RDB) via Butyric Acids: Process Engineering Analysis DMR Pretreatment, Batch Enzymatic Hydrolysis, Hydrolysate Clarification, Anaerobic Bioconversion, Catalytic Upgrading, Lignin Conversion to Coproducts \\ All Values in 2016\$ \\ Minimum Fuel Selling Price (MFSP, Gasoline-Equivalent \\ Basis): \\ Contributions: Feedstock \\ Fuel Conversion \\ Coproduct Conversion \\ Fuel Production \\ Fuel Yield \\ Adipic Acid Coproduct Yield \\ Butyric Acid Process Yield [Theoretical Yield] \\ Feedstock + Handling Cost Internal Rate of Return (After-Tax) \\ Equity Percent of Total Investment \\ $\$ 10.02$ /GGE \\ $\$ 2.09 / \mathrm{GGE}$ \\ $\$ 5.23 / \mathrm{GGE}$ \\ $\$ 2.71 / \mathrm{GGE}$ \\ 27.8 MMGGE per year (at $68^{\circ} \mathrm{F}$ ) \\ 38.4 GGE / dry U.S. ton feedstock \\ $40 \mathrm{lb} /$ dry U.S. ton feedstock \\ 0.44 [0.49] kg Acid/kg Total Sugars (89\% of theoretical) $\$ 80.10$ /dry U.S. ton feedstock \\ $10 \%$ \\ $40 \%$}

\begin{tabular}{|c|c|}
\hline \multicolumn{2}{|l|}{ Capital Costs } \\
\hline Area 200: Pretreatment & $\$ 51,445,817$ \\
\hline Area 300: Sugar Hydrolysis and Conditioning & $\$ 82,903,853$ \\
\hline Area 400: Enzyme Production & $\$ 11,520,765$ \\
\hline Area 500: Bioconversion and Upgrading & $\$ 49,002,750$ \\
\hline Area 600: Wastewater & $\$ 57,196,958$ \\
\hline Area 700: Lignin & $\$ 266,685,162$ \\
\hline Area 800: Boiler & $\$ 39,090,004$ \\
\hline Area 900: Utilities \& Storage & $\$ 12,986,711$ \\
\hline Total Installed Equipment Cost & $\$ 570,832,020$ \\
\hline Added Direct + Indirect Costs & $\$ 525,667,980$ \\
\hline$(\%$ of $\mathrm{TCl})$ & $48 \%$ \\
\hline Total Capital Investment (TCI) & $\$ 1,096,500,000$ \\
\hline Installed Equipment Cost/Annual GGE & $\$ 20.53$ \\
\hline Total Capital Investment/Annual GGE & $\$ 39.43$ \\
\hline Operating Hours Per Year (On-Stream Factor) & $7884(90 \%)$ \\
\hline Loan Rate & $8.0 \%$ \\
\hline Term (years) & 10 \\
\hline Capital Charge Factor (Computed) & 0.127 \\
\hline Fuel Carbon Retention Efficiencies: & \\
\hline From Hydrolysate Sugar (Fuel C / Sugar C) & $46.1 \%$ \\
\hline From Biomass (Fuel C / Biomass C) & $22.4 \%$ \\
\hline Adipic Acid Carbon Efficiency from Biomass & $2.2 \%$ \\
\hline Maximum Yields ( $100 \%$ of Theoretical) ${ }^{a}$ & \\
\hline Fuel Production (U.S. ton/yr) & 128,798 \\
\hline Current Fuel Production (U.S. ton/yr) ${ }^{b}$ & 85,310 \\
\hline Current Yield (Actual/Theoretical) & $66.2 \%$ \\
\hline${ }^{a}$ Complete conversion of biomass carbohydr & fuel \\
\hline $\begin{array}{l}{ }^{b} \text { Recovered fuel yield after concentration, se } \\
\text { (Theoretical yields above do not consider } \\
\text { losses during product upgrading and purif }\end{array}$ & $\begin{array}{l}\text { hydrotreating } \\
\text { oss recovery }\end{array}$ \\
\hline
\end{tabular}

Manufacturing Costs (cents/GGE fuel product)

Feedstock + Handling 208.6

Sulfuric Acid $\quad 33.5$

Caustic

Sodium Carbonate $\quad 35.55$

Glucose (enzyme production) 30.1

Hydrogen 0.0

Electricity (import) 104.1

Other Raw Materials $\quad 73.0$

Catalysts 3.1

Waste Disposal

Na2SO4 Coproduct $\quad-67.7$

Adipic Acid coproduct $(\$ 0.86 / \mathrm{lb}) \quad-89.5$

Fixed Costs 98.0

Capital Depreciation $\quad 125.1$

Average Income Tax 37.4

Average Return on Investment $\quad 338.5$

$\begin{array}{lr}\text { Total } & 1002.1\end{array}$

Manufacturing Costs $(\$ / \mathrm{yr})$

Feedstock + Handling $\$ 58,000,000$

Sulfuric Acid $\$ \$ 9,300,000$

Caustic $\$ \$ 18,700,000$

Glucose (enzyme production) \$8,400,000

Hydrogen $\$ 0$

Electricity (import) $\$ 29,000,000$

Other Raw Materials $\$ \$ 20,300,000$

Catalysts $\$ \$ 900,000$

Waste Disposal $\$ 1,500,000$

Na2SO4 Coproduct $\quad-\$ 18,800,000$

Adipic Acid coproduct $(\$ 0.86 / \mathrm{lb}) \quad-\$ 24,900,000$

Fixed Costs $\$ 27,200,000$

Capital Depreciation $\$ 34,800,000$

Average Income Tax $\$ 10,400,000$

Average Return on Investment $\$ \$ 94,100,000$

Total $\$ 268,900,000$

Specific Operating Conditions

\begin{tabular}{ll}
\hline Enzyme Loading (mg/g cellulose) & 10.0 \\
Net Electricity Import (kWh/GGE) & 15.5 \\
Plant Electricity Use (kWh/GGE) & 18.7 \\
Metabolic Yield (g/g substrate) & \\
$\quad$ Glucose to Butyric & 0.465 \\
Glucose to Biomass & 0.021 \\
Xylose to Butyric & 0.465 \\
Xylose to Biomass & 0.021 \\
Arabinos to Butyric & 0.108 \\
Arabinos to Biomass & 0.074
\end{tabular}




\section{Acids Pathway (Convert Lignin - "High") \\ Biological Renewable Diesel Blendstock (RDB) via Butyric Acids: Process Engineering Analysis DMR Pretreatment, Batch Enzymatic Hydrolysis, Hydrolysate Clarification, Anaerobic Bioconversion, Catalytic Upgrading, Lignin Conversion to Coproducts \\ All Values in $2016 \$$ \\ Minimum Fuel Selling Price (MFSP, Gasoline-Equivalent \\ Basis): \\ Contributions: Feedstock \\ Fuel Conversion \\ Coproduct Conversion \\ Fuel Production \\ Fuel Yield \\ Adipic Acid Coproduct Yield \\ Butyric Acid Process Yield [Theoretical Yield] \\ Feedstock + Handling Cost \\ Internal Rate of Return (After-Tax) \\ Equity Percent of Total Investment \\ $\$ 9.04$ /GGE
\$2.09/GGE
$\$ 5.23 / \mathrm{GGE}$
$\$ 1.72$ /GGE \\ 27.8 MMGGE per year (at $68^{\circ} \mathrm{F}$ ) \\ 38.4 GGE / dry U.S. ton feedstock \\ $40 \mathrm{lb} /$ dry U.S. ton feedstock \\ 0.44 [0.49] kg Acid/kg Total Sugars (89\% of theoretical) $\$ 80.10 /$ dry U.S. ton feedstock \\ $10 \%$ \\ $40 \%$}

\begin{tabular}{|c|c|}
\hline \multicolumn{2}{|l|}{ Capital Costs } \\
\hline Area 200: Pretreatment & $\$ 51,445,817$ \\
\hline Area 300: Sugar Hydrolysis and Conditioning & $\$ 82,903,853$ \\
\hline Area 400: Enzyme Production & $\$ 11,520,765$ \\
\hline Area 500: Bioconversion and Upgrading & $\$ 49,002,750$ \\
\hline Area 600: Wastewater & $\$ 57,192,311$ \\
\hline Area 700: Lignin & $\$ 172,157,673$ \\
\hline Area 800: Boiler & $\$ 39,102,124$ \\
\hline Area 900: Utilities \& Storage & $\$ 12,991,307$ \\
\hline Total Installed Equipment Cost & $\$ 476,316,599$ \\
\hline Added Direct + Indirect Costs & $\$ 433,683,401$ \\
\hline$(\%$ of $\mathrm{TCl})$ & $48 \%$ \\
\hline Total Capital Investment (TCI) & $\$ 910,000,000$ \\
\hline Installed Equipment Cost/Annual GGE & $\$ 17.13$ \\
\hline Total Capital Investment/Annual GGE & $\$ 32.72$ \\
\hline Operating Hours Per Year (On-Stream Factor) & $7884(90 \%)$ \\
\hline Loan Rate & $8.0 \%$ \\
\hline Term (years) & 10 \\
\hline Capital Charge Factor (Computed) & 0.127 \\
\hline Fuel Carbon Retention Efficiencies: & \\
\hline From Hydrolysate Sugar (Fuel C / Sugar C) & $46.1 \%$ \\
\hline From Biomass (Fuel C / Biomass C) & $22.4 \%$ \\
\hline Adipic Acid Carbon Efficiency from Biomass & $2.2 \%$ \\
\hline Maximum Yields ( $100 \%$ of Theoretical) ${ }^{a}$ & \\
\hline Fuel Production (U.S. ton/yr) & 128,798 \\
\hline Current Fuel Production (U.S. ton/yr) ${ }^{\mathrm{b}}$ & 85,310 \\
\hline Current Yield (Actual/Theoretical) & $66.2 \%$ \\
\hline${ }^{a}$ Complete conversion of biomass carbohydra & \\
\hline $\begin{array}{l}{ }^{b} \text { Recovered fuel yield after concentration, sel } \\
\text { (Theoretical yields above do not consider } \\
\text { losses during product upgrading and purifi }\end{array}$ & $\begin{array}{l}\text { ydrotreating } \\
\text { s recovery }\end{array}$ \\
\hline
\end{tabular}

Manufacturing Costs (cents/GGE fuel product)

Feedstock + Handling 208.6

Sulfuric Acid $\quad 33.5$

Caustic 671

Sodium Carbonate $\quad 35.55$

Glucose (enzyme production) 30.1

Hydrogen $\quad 0.0$

Electricity (import) 105.0

Other Raw Materials $\quad 73.0$

Catalysts 3.1

Waste Disposal

Na2SO4 Coproduct $\quad-67.7$

Adipic Acid coproduct $(\$ 0.86 / \mathrm{lb}) \quad-89.5$

Fixed Costs

Capital Depreciation $\quad 103.6$

Average Income Tax 31.2

Average Return on Investment $\quad 282.2$

Total 904.2

Manufacturing Costs $(\$ / \mathrm{yr})$

Feedstock + Handling $\$ 58,000,000$

Sulfuric Acid $\$ \$ 9,300,000$

Caustic $\$ 18,700,000$

Glucose (enzyme production) \$8,400,000

Hydrogen $\$ 0$

Electricity (import) $\$ 29,200,000$

Other Raw Materials $\$ \$ 20,300,000$

Catalysts $\quad \$ 900,000$

Waste Disposal $\$ 1,500,000$

Na2SO4 Coproduct $\quad-\$ 18,800,000$

Adipic Acid coproduct $(\$ 0.86 / \mathrm{lb}) \quad-\$ 24,900,000$

Fixed Costs $\$ 23,200,000$

Capital Depreciation $\$ 28,800,000$

Average Income Tax $\$ 8,700,000$

Average Return on Investment $\$ \$ 78,500,000$

Total $\$ 241,800,000$

Specific Operating Conditions

\begin{tabular}{ll}
\hline Enzyme Loading (mg/g cellulose) & 10.0 \\
Net Electricity Import (kWh/GGE) & 15.6 \\
Plant Electricity Use (kWh/GGE) & 18.8 \\
Metabolic Yield (g/g substrate) & \\
$\quad$ Glucose to Butyric & 0.465 \\
$\quad$ Glucose to Biomass & 0.021 \\
Xylose to Butyric & 0.465 \\
Xylose to Biomass & 0.021 \\
Arabinos to Butyric & 0.108 \\
Arabinos to Biomass & 0.074
\end{tabular}




\section{Appendix B. Life Cycle Inventory (LCI) for 2020 SOT Benchmark Models}

\begin{tabular}{|c|c|c|c|c|}
\hline & $\begin{array}{l}2020 \text { SOT } \\
\text { (Burn } \\
\text { Lignin) }\end{array}$ & $\begin{array}{c}2020 \text { SOT } \\
\text { (Convert } \\
\text { Lignin - } \\
\text { Base) }\end{array}$ & $\begin{array}{c}2020 \text { SOT } \\
\text { (Convert } \\
\text { Lignin - } \\
\text { High) }\end{array}$ & \\
\hline Products & \multicolumn{4}{|c|}{ Production Rate } \\
\hline Hydrocarbon fuel & $\begin{array}{c}10,525 \\
111\end{array}$ & $\begin{array}{c}10,558 \\
112\end{array}$ & $\begin{array}{c}10,558 \\
112\end{array}$ & $\begin{array}{l}\mathrm{kg} / \mathrm{hr} \\
\mathrm{MM} \mathrm{kcal} / \mathrm{hr}(\mathrm{LHV})\end{array}$ \\
\hline \multicolumn{5}{|l|}{ Co-products } \\
\hline Adipic acid (polymer grade) & 0 & 1,641 & 1,641 & $\mathrm{~kg} / \mathrm{hr}$ \\
\hline Recovered sodium sulfate salt from WWT & 10,573 & 14,382 & 14,381 & $\mathrm{~kg} / \mathrm{hr}$ \\
\hline Export electricity & - & - & - & $\mathrm{kW}$ \\
\hline Resource Consumption & \multicolumn{4}{|c|}{ Flow Rate (kg/hr) } \\
\hline Biomass Feedstock (20\% moisture) & 104,167 & 104,167 & 104,167 & \\
\hline Sulfuric acid, $93 \%$ & 9,235 & 11,542 & 11,542 & \\
\hline Caustic (as pure) & 2,000 & 3,786 & 3,786 & \\
\hline Sodium carbonate & 6,667 & 6,667 & 6,667 & \\
\hline Ammonia & 1,168 & 2,125 & 2,125 & \\
\hline Glucose & 1,312 & 1,312 & 1,312 & \\
\hline Corn steep liquor & 918 & 918 & 918 & \\
\hline Corn oil & 7 & 7 & 7 & \\
\hline Host nutrients & 37 & 37 & 37 & \\
\hline Sulfur dioxide & 9 & 9 & 9 & \\
\hline Diammonium phosphate & 103 & 206 & 206 & \\
\hline Flocculant & 435 & 436 & 436 & \\
\hline Toluene solvent makeup & 0 & 0 & 0 & \\
\hline Hydrogen & 848 & 990 & 990 & \\
\hline Ethanol & 0 & 13 & 13 & \\
\hline Boiler chemicals & 0 & 1 & 1 & \\
\hline FGD lime & 109 & 180 & 180 & \\
\hline WWT polymer & 34 & 0 & 0 & \\
\hline Cooling tower chemicals & 2 & 2 & 2 & \\
\hline Makeup water & 134,676 & 112,362 & 112,353 & \\
\hline Natural gas for boiler & 0 & 4,400 & 4,400 & \\
\hline Natural gas for hot oil system & 0 & 0 & 0 & MMBtu/hr \\
\hline Grid electricity (net import) & 17,894 & 42,759 & 43,213 & $\mathrm{~kW}$ \\
\hline Waste Streams & \multicolumn{4}{|c|}{ Flow Rate (kg/hr) } \\
\hline Disposal of ash & 4,290 & 4,408 & 4,408 & \\
\hline Air Emissions & \multicolumn{4}{|c|}{ Flow Rate (kg/hr) } \\
\hline $\mathrm{H}_{2} \mathrm{O}$ & 96,354 & 96,779 & 96,848 & \\
\hline $\mathrm{N}_{2}$ & 509,124 & 424,248 & 424,225 & \\
\hline $\mathrm{CO}_{2}$ (biogenic) & 108,586 & 116,835 & 116,835 & \\
\hline $\mathrm{O}_{2}$ & 80,155 & 35,641 & 35,633 & \\
\hline $\mathrm{NO}_{2}$ & 23 & 35 & 35 & \\
\hline $\mathrm{SO}_{2}$ & 7 & 12 & 12 & \\
\hline $\mathrm{CO}$ & 81 & 59 & 59 & \\
\hline $\mathrm{CH}_{4}$ & 3 & 0 & 0 & \\
\hline
\end{tabular}




\begin{tabular}{|c|c|c|c|c|}
\hline & $\begin{array}{c}2020 \text { SOT } \\
\text { (Burn Lignin) }\end{array}$ & $\begin{array}{l}2020 \text { SOT } \\
\text { (Convert } \\
\text { Lignin - } \\
\text { Base) }\end{array}$ & $\begin{array}{l}2020 \text { SOT } \\
\text { (Convert } \\
\text { Lignin - } \\
\text { High) }\end{array}$ & \\
\hline Products & Production Rate & & & \\
\hline Hydrocarbon Fuel & $\begin{array}{c}9,833 \\
103\end{array}$ & $\begin{array}{c}9,815 \\
103\end{array}$ & $\begin{array}{c}9,815 \\
103\end{array}$ & $\begin{array}{l}\mathrm{kg} / \mathrm{hr} \\
\mathrm{MM} \mathrm{kcal} / \mathrm{hr}(\mathrm{LHV})\end{array}$ \\
\hline $\begin{array}{l}\text { Co-products } \\
\text { Adipic acid (polymer grade) } \\
\text { Recovered sodium sulfate salt from WWT } \\
\text { Export electricity }\end{array}$ & $\begin{array}{c}0 \\
10,304 \\
-\end{array}$ & $\begin{array}{c}1,673 \\
15,331 \\
-\end{array}$ & $\begin{array}{c}1,673 \\
15,331 \\
-\end{array}$ & $\begin{array}{l}\mathrm{kg} / \mathrm{hr} \\
\mathrm{kg} / \mathrm{hr} \\
\mathrm{kW}\end{array}$ \\
\hline Resource Consumption & Flow Rate $(\mathrm{kg} / \mathrm{hr}$ & & & \\
\hline Biomass Feedstock (20\% moisture) & 104,167 & 104,167 & 104,167 & \\
\hline Sulfuric acid, $93 \%$ & 9,235 & 12,477 & 12,477 & \\
\hline Caustic (as pure) & 2,000 & 4,501 & 4,501 & \\
\hline Sodium carbonate & 6,667 & 6,667 & 6,667 & \\
\hline Ammonia & 1,261 & 2,238 & 2,238 & \\
\hline Glucose & 1,312 & 1,312 & 1,312 & \\
\hline Corn steep liquor & 1,226 & 1,226 & 1,226 & \\
\hline Corn oil & 7 & 7 & 7 & \\
\hline Host nutrients & 37 & 37 & 37 & \\
\hline Sulfur dioxide & 9 & 9 & 9 & \\
\hline Diammonium phosphate & 169 & 273 & 273 & \\
\hline Flocculant & 407 & 407 & 407 & \\
\hline Toluene solvent makeup & 90 & 90 & 90 & \\
\hline Hydrogen & 0 & 0 & 0 & \\
\hline Ethanol & 0 & 13 & 13 & \\
\hline Boiler chemicals & 0 & 0 & 0 & \\
\hline FGD lime & 111 & 194 & 194 & \\
\hline WWT polymer & 37 & 0 & 0 & \\
\hline Cooling tower chemicals & 3 & 2 & 2 & \\
\hline Makeup water & 330,952 & 239,435 & 239,742 & \\
\hline Natural gas for boiler & 0 & 0 & 0 & \\
\hline Natural gas for hot oil system & 39 & 39 & 39 & MMBtu/hr \\
\hline Grid electricity (net import) & 7,019 & 53,859 & 54,310 & $\mathrm{~kW}$ \\
\hline Waste Streams & Flow Rate $(\mathrm{kg} / \mathrm{hr}$ & & & \\
\hline Disposal of Ash & 4,294 & 4,432 & 4,432 & \\
\hline Air Emissions & Flow Rate $(\mathrm{kg} / \mathrm{hr}$ & & & \\
\hline $\mathrm{H}_{2} \mathrm{O}$ & 125,107 & 94,042 & 94,111 & \\
\hline $\mathrm{N}_{2}$ & 485,922 & 600,881 & 600,858 & \\
\hline $\mathrm{CO}_{2}$ (biogenic) & 112,524 & 109,622 & 109,622 & \\
\hline $\mathrm{O}_{2}$ & 75,224 & 108,819 & 108,812 & \\
\hline $\mathrm{NO}_{2}$ & 47 & 7 & 7 & \\
\hline $\mathrm{SO}_{2}$ & 8 & 12 & 12 & \\
\hline $\mathrm{CO}$ & 83 & 35 & 35 & \\
\hline $\mathrm{CH}_{4}$ & 2 & 0 & 0 & \\
\hline
\end{tabular}

